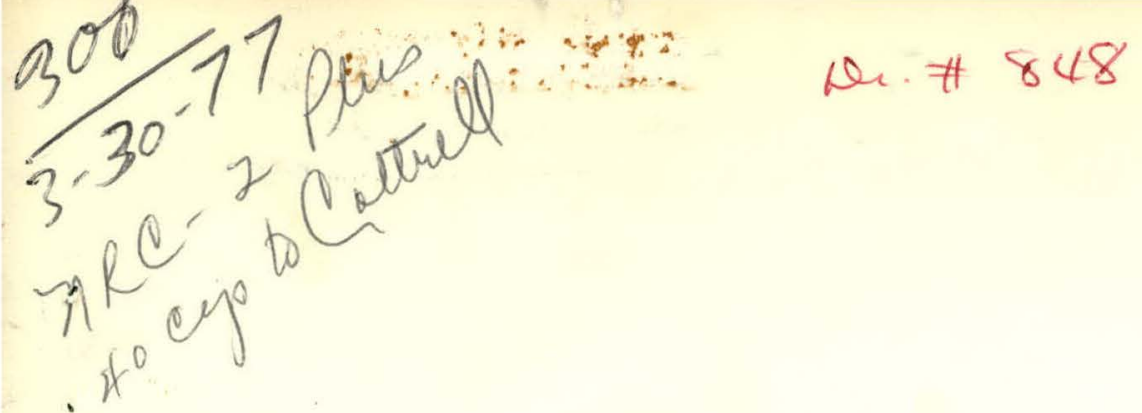

\title{
ANALYSIS OF SEMISCALE MOD-1 INTEGRAL TEST WITH ASYMMETRICAL BREAK (TEST S-29-1)
}

\author{
MICHAEL A. LANGERMAN
}

March 1977

\section{MASTER}

EGEG Idaho, Inc.

IDAHO NATIONAL ENGINEERING LABORATORY 


\section{DISCLAIMER}

This report was prepared as an account of work sponsored by an agency of the United States Government. Neither the United States Government nor any agency Thereof, nor any of their employees, makes any warranty, express or implied, or assumes any legal liability or responsibility for the accuracy, completeness, or usefulness of any information, apparatus, product, or process disclosed, or represents that its use would not infringe privately owned rights. Reference herein to any specific commercial product, process, or service by trade name, trademark, manufacturer, or otherwise does not necessarily constitute or imply its endorsement, recommendation, or favoring by the United States Government or any agency thereof. The views and opinions of authors expressed herein do not necessarily state or reflect those of the United States Government or any agency thereof. 


\section{DISCLAIMER}

Portions of this document may be illegible in electronic image products. Images are produced from the best available original document. 
Printed in the United States of America Available from

National Technical Information Service

U.S. Department of Commerce

5285 Port Royal Road

Springfield, Virginia 22161

Price: Printed Copy $\$ 4.00$; Microfiche $\$ 3.00$

"The NRC will make available data tapes and operational computer codes on research programs dealing with postulated loss-of-coolant accidents in light water reactors. Persons requesting this information must reimburse the NRC contractors for their expenses in preparing copies of the data tapes and the operational computer codes. Requests should be submitted to the Research Applications Branch, Office of Nuclear Regulatory Research, Nuclear Regulatory Commission, Washington, D.C. 20555."

\section{NOTICE}

This report was prepared as an account of work sponsored by the United States Government. Neither the United States nor the Energy Research and Development Administration, nor the Nuclear Regulatory Commission, nor any of their employees, nor any of their contractors, subcontractors, or their employees, makes any warranty, express or implied, or assumes any legal liability or responsibility for the accuracy, completeness or usefulness of any information, apparatus, product or process disclosed, or represents that its use would not infringe privately owned rights. 
TREE-NUREG-1076

\section{ANALYSIS OF SEMISCALE MOD-1 INTEGRAL TEST}

WITH ASYMMETRICAL BREAK (TEST S-29-1)
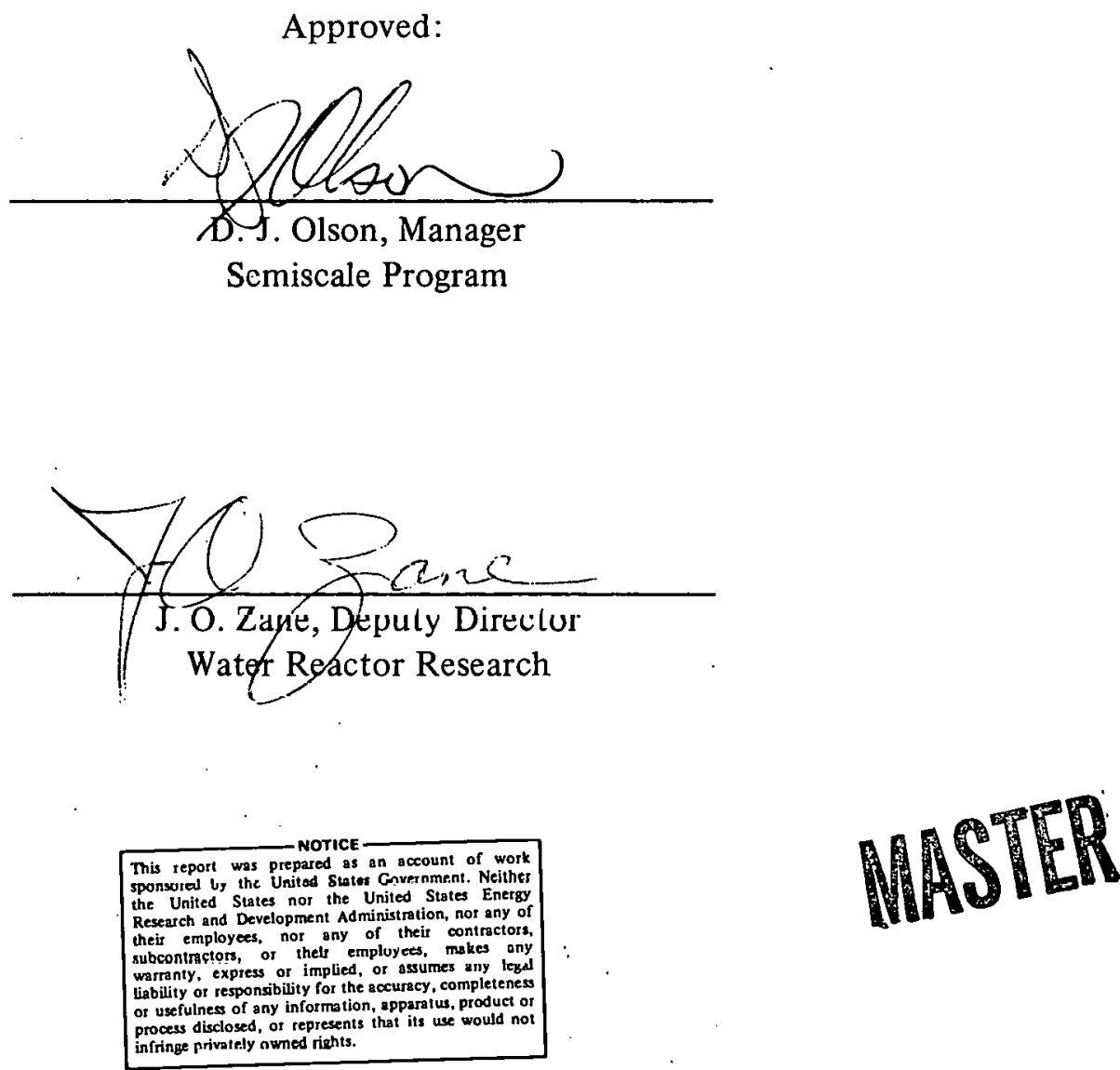
Water Reactor Safety Research

Systems Engineering

\section{ANALYSIS OF SEMISCALE MOD-1 INTEGRAL TEST \\ WITH ASYMMETRICAL BREAK (TEST S-29-1)}

by

Michael A. Langerman

EG\&G IDAHO, INC.

March 1977

PREPARED FOR THE

U.S. NUCLEAR REGULATORY COMMISSION

AND

ENERGY RESEARCH AND DEVELOPMENT ADMINISTRATION

IDAHU UPEKAIIUNSS UFFICE

UNDER CONTRACT NO. EY-76-C-07-1570 


\begin{abstract}
Selected experimental data obtained from Semiscale Mod-1 cold leg break Test S-29-1 and results obtained from analytical codes are analyzed. This test was the first integral blowdown reflood test conducted with the Mod-1 system and was a special test designed specifically to evaluate the sensitivity of the early Mod-1 core thermal response ( 0 to $5 \mathrm{sec}$ after rupture) to the magnitude and direction of the core flow. To achieve this specific objective in Test S-29-1, the vessel side break area was reduced to approximately one-half the scaled break area associated with a $200 \%$ cold leg break test. The reduction in break area significantly reduced the core flow reversal that took place immediately after rupture and resulted in periods of positive core flow in the early portion of the test. The results obtained from this test are compared with results obtained from a $200 \%$ cold leg break test and the effect of core flow on early core thermal response is evaluated. Since Test S-29-1 was the first integral blowdown reflood test conducted with the Mod-1 system, data are also presented through the reflood stage of the test and the results are analyzed. The test data and the core thermal response calculated with the RELAP4 code are also compared.
\end{abstract}




\section{SUMMARY}

The Semiscale Mod-1 program was designed to investigate the behavior of a pressurized water reactor system (PWR) model during an hypothesized loss-of-coolant accident (LOCA). The Mod-1 system is a scaled down model of a PWR that simulates the principal physical features of a nuclear plant, and is designed such that all facets of the accident may be investigated. Nuclear heating is simulated in the tests by a core composed of an array of electrically heated rods. The core is contained in a pressure vessel which also includes a downcomer, lower plenum, and upper plenum. The system piping is arranged in a 1-1/2-loop configuration with the intact loop containing an active steam generator and pump, and with the broken loop containing passive simulators for the steam generator and pump.

Test S-29-1 was the first integral blowdown reflood test conducted on the Semiscale Mod-1 system and was a special test conducted specifically to evaluate the sensitivity of the early thermal response of the Mod-1 core to the early core flow behavior. This sensitivity analysis was accomplished by altering the core flow in Test S-29-1 from that of previous cold leg break tests by reducing the size of the vessel side break area. The test results obtained were then compared with the results obtained from a 200\% cold leg break test (Test S-02-7), which had essentially the same prerupture conditions, to determine any difference in early core thermal response caused by the different core inlet flows. The results were also compared with calculations obtained from the Semiscale RELAP4 system model and a special Semiscale core model. Since Test S-29-1 was the first integral blowdown reflood test conducted on the Semiscale Mod-1 system, data were recorded and evaluated through the reflood stage of the test.

The Semiscale Mod-1 system was arranged in a cold leg break configuration for Test S-29-1. The procedure followed in the approach to the test was: (a) the system was brought up to pressure $(2250 \mathrm{psig})$, desired flow rate, and an isothermal temperature of about $544^{\circ} \mathrm{F}$; (b) core power was increased in successive steps to $1.54 \mathrm{MW}$; (c) core power and core flow rate were adjusted to attain the desired core differential temperature of about $66^{\circ} \mathrm{F}$ and the system was allowed to equilibrate; and (d) after the desired initial steady state conditions had been attained, the system was subjected to decompression by introducing a leak in the broken loop cold leg. As the test proceeded, emergency core coolant (ECC) was injected into the intact and broken loop cold legs.

The magnitude of the core flow reversal that took place shortly after rupture in Test S-29-1 was significantly lower than the reversal that took place in Test S-02-7. The reduction in the core flow reversal in Test $S-29-1$ was a direct result of the reduced vessel side break mass flow rate caused by the smaller break area. The magnitude of the core flow reversal continued to decline following rupture in Test S-29-1 until about $6 \mathrm{sec}$ when low quality fluid from the lower plenum began to flow in the positive (upward) core direction. This high density positive core flow in Test S-29-1 lasted until about $30 \mathrm{sec}$ after rupture and resulted in a high core steam generation rate and low system depressurization rate compared with results from Test S-02-7. 
The early $(0$ to $5 \mathrm{sec}$ ) thermal response of the Mod-1 core was not appreciably influenced by the magnitude of the core flow reversal that took place in Test S-29-1. In a typical short term cladding temperature response comparison, the data in both Tests S-29-1 and S-02-7 indicated critical heat flux (CHF) was reached in less than $1 \mathrm{sec}$ following rupture and the early (up to $5 \mathrm{sec}$ following rupture) post-CHF heat transfer was essentially the same in the two tests. However, when the core flow return to the positive direction at about $6 \mathrm{sec}$ in Test S-29-1, the rod-to-fluid heat transfer in the core increased significantly. This increase in rod-to-fluid heat transfer was followed shortly by a rod quench behavior at and below the 21 -in. core elevations. Due to the nonhomogeneous flow regime present, the RELAP4 homogeneous system model was inadequate in calculating the core response during this period of the blowdown transient.

The high corc heat transfer rates in Test S-29-1 that took place shortly after the corc flow returned to the positive direction resulted in a high rate of core steam generation which prolonged the blowdown transient. This long blowdown time appeared to have greatly reduced the effectiveness of the emergency core cooling (ECC) systems. However, the consequences of the reduced ECC system efficiency were minimized by the increased efficiency in.core heat transfer during blowdown. 


\section{CONTENTS}

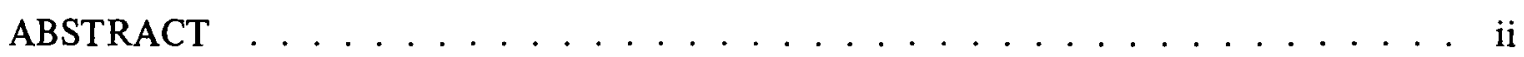

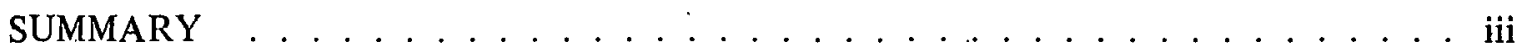

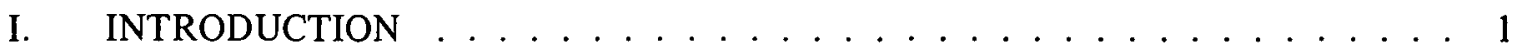

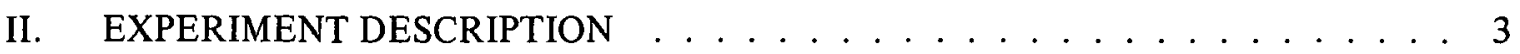

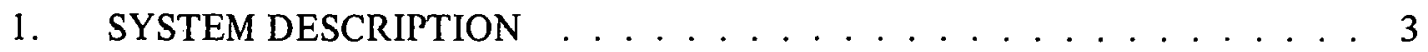

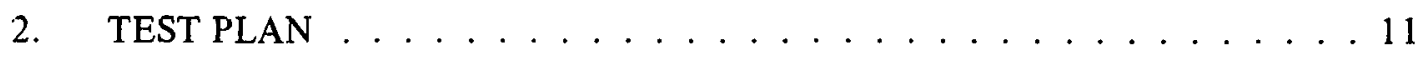

III. TEST RESULTS . . . . . . . . . . . . . . . . . . . 12

1. GENERAL SYSTEM HYDRAULIC RESPONSE DURING THE BLOWDOWN TRANSIENT IN TEST S-29-1 . . . . . . . . . . 12

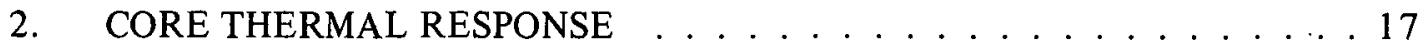

3. REFILL AND REFLOOD BEHAVIOR . . . . . . . . . . . . 24

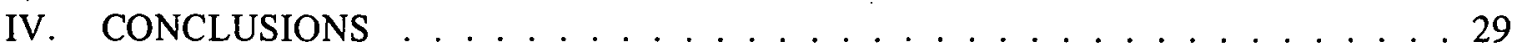

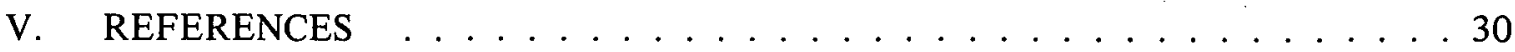

APPENDIX A - DESCRIPTION OF THE RELAP4/MOD-5

UPDATE 1 ANALYTICAL MODEL AS APPLIED FOR

TEST S-29-1 CALCULATIONS $\ldots \ldots \ldots \ldots . \ldots . \ldots . \ldots . \ldots$

\section{FIGURES}

1. Semiscale Mod-1 system configuration for Test $\mathrm{S}-29-1 \ldots \ldots \ldots$

2. Vessel cross section and core layout ................. . . 5

3. Semiscale Mod-1 electric heater $\operatorname{rod} \ldots \ldots \ldots \ldots$

4. Cross section of the vessel with core ................. 7

5. Scmiscale Mod-1 heater rod axial power distribution . . . . , , , . . 8 
6. Semiscale Mod-1 heater core - plan

view showing instrumentation . . . . . . . . . . . . . . . . . 9

7. Mass flow rate at the vessel side

break - Tests S-29-1 and $\mathrm{S}-02-7 \ldots \ldots \ldots \ldots$

8. Fluid temperature near the broken loop cold leg vessel

inlet versus the cold leg saturation temperature - Test S-02-7 . . . . . . . . 14

9. Fluid temperature near the broken loop cold leg vessel

inlet versus the cold leg saturation temperature - Test S-29-1 . . . . . . . . 15

10. Volumetric flow rate near the core

inlet - Tests S-29-1 and S-02-7

11. Fluid density near the core inlet - Tests S-29-1 and S-02-7 . . . . . . . 16

12. Upper plenum pressure - Tests $S-29-1$ and $S-02-7 \ldots \ldots$. . . . . . . 16

13. Mass flow rate near the pump side

break - Tests $\mathrm{S}-29-1$ and $\mathrm{S}-02-7 \ldots \ldots \ldots \ldots 17$

14. Cladding temperature at the 29-in. elevation on Rod B6

$(-1$ to 5 seconds $)-$ Tests $\mathrm{S}-29-1$ and $\mathrm{S}-02-7 \ldots \ldots \ldots 18$

15. Cladding temperature at the 9-in. elevation on

Rod E-G - Tests S-29-1 and S-02-7 . . . . . . . . . . . . . . 19

16. Cladding temperature at the 29-in: elevation on

Rod B6 (-6 to 45 seconds) - Tests S-29-1 and S-02-7 . . . . . . . . . . . . 19

17. Mass flow rate near the core

inlet - Tést S-2.9-1 and RELAP4 calculation . . . . . . . . . . . 20

18. Fluid density near the core

inlet - Test S-29-1 and RELAP4 calculation . . . . . . . . . . . 21

19. Cladding temperature at the 29-in. elevation on

Ròd B6 - Tést S-29-1 and RELAP4 calculation . . . . . . . . . . . . 21

20. Semiscale special core model nodalization diagram . . . . . . . . . . . 22

21. Cladding temperature in the rod high power zone - special core model calculation . . . . . . . . . . . . . . 23 
22. System pressure and fluid velocity in the

downcomer - Test S-29-1 . . . . . . . . . . . . . . 25

23. System pressure, pressure suppression

tank pressure, and lower plenum density

(172 in. below cold leg centerline) - Test S-29-1 . . . . . . . . . . 25

24. Volumetric flow rate in the intact loop accumulator

line - Test $S-29-1 \ldots \ldots \ldots$. . . . . . . . . . . . 26

25. Rod cladding temperature at the initiation of reflood

versus axial core elevation - Test $\mathrm{S}-29-1 \ldots \ldots$. . . . . . . . . . 27

26. Fluid density near the core inlet

(0 to 200 seconds) - Test $\mathrm{S}-29-1 \ldots \ldots$. . . . . . . . . . 27

27. Rod cladding temperature at the 5-, 20-, 21-, and 26-in. core elevations on Rods B4, E3, E5, and F5, respectively - Test S-29-1 . . . . . . . . . . . . . . 28

A-1. RELAP4 model of semiscale system for Test $\mathrm{S}-29-1 \ldots \ldots$. . . . . . . . . 34

A-2. Semiscale RELAP4 model of heated core configuration for Test S-29-1 . . . . . . . . . . . . . . 37

\section{TABLES}

I. Initial Conditions and ECC Parameters for Test S-29-1 . . . . . . . . 10

II. Description of Boundary Conditions and Options Used in Test S-29-1 Core Model . . . . . . . . . . . . . . . . . . . 23

A-I. RELAP4 Control Volume Description . . . . . . . . . . . . . . 35

A-II. RELAP4 Fill System Description . . . . . . . . . . . . . . 37 


\section{ANALYSIS OF SEMISCALE MOD-1 INTEGRAL TEST}

\section{WITH ASYMMETRICAL BREAK (TEST S-29-1)}

\section{INTRODUCTION}

The Semiscale Mod-1 experimental program conducted by EG\&G Idaho, Inc., is part of the overall U.S. Nuclear Regulatory Commission (NRC) and Energy Research and Development Administration (ERDA) sponsored research and development program to investigate the behavior of the pressurized water reactor (PWR) system during an hypothesized loss-of-coolant accident (LOCA). Emphasis for the Semiscale Mod-1 program is placed on acquiring system effects data, using a small scale nonnuclear experimental system, that characterize the most significant thermal-hydraulic phenomena likely to occur in the primary coolant system of a PWR during the depressurization (blowdown) and emergency core cooling (ECC) phases of a LOCA. The experimental data obtained from this program are intended to be used primarily to evaluate the adequacy of analytical models which have been developed to describe LOCA phenomena in the overall system as well as in the individual system components. Selected experimental data produced by this program will also be used to aid other ERDA-NRC-sponsored experimental programs, such as the Loss-of-Fluid Test (LOFT) program ${ }^{[1]}$, in optimizing test series, selecting test parameters, and evaluating test results.

The Semiscale Mod-1 experimental investigations are performed with a system which simulates the principal physical features of a nuclear plant but which is much smaller in volume. Nuclear heating is simulated in the tests by a core composed of an array of electrically heated rods. The core is contained in a pressure vessel which also includes a downcomer, lower plenum, and upper plenum. The system piping is arranged in a 1-1/2-loop configuration with the intact loop containing an active steam generator and pump, and with the broken loop containing passive simulators for the steam generator and pump.

Test S-29-1 was the first integral blowdown reflood test conducted in the Mod-1 system. It was a special test designed specifically to determine the sensitivity of the early core thermal response to a substantial alteration in core inlet flow from that obtained from previous $200 \%$ cold leg break tests. Although the sensitivity of the core thermal response to core inlet flow magnitude and direction has been a subject of a previous analysis ${ }^{[2]}$, that previous analysis dealt primarily with core flows that differed because of break location. Prior to Test S-29-1, no experimental data were available to assess changes in either the core critical heat flux (CHF) behavior or the core post-CHF heat transfer that resulted from a substantial change in core flow during cold leg break tests. Since no tests were scheduled with this objective in mind, and because the question was considered of sufficient importance that a timely answer was needed, a special test was conducted. 
To achieve the desired change in the core flow for Test S-29-1, the vessel side break area was reduced to approximately one-half the vessel side break area associated with a $200 \%$ cold leg break test with the intention of significantly reducing the magnitude of the core flow reversal that would take place after rupture. The degree of reduction in the vessel side break area which would produce a core flow alteration sufficient for this evaluation was determined through analytical calculations. Since Test S-29-1 was the first integral blowdown reflood test conducted in the Mod-1 system, it had as a secondary objective the investigation of the Semiscale system behavior from the initiation of blowdown to the final stages of reflood. To accomplish this secondary objective, ECC water was injected into the intact and broken loop cold legs.

This report presents an cvaluation of the important events that took place during Test S-29-1 as they relate to primary and secondary objectives; uninterpreted test data may be obtained from Reference 3. To illustrate the effect of the altered core flow on core heat transfer during the depressurization period of the test, results from Test S-29-1 are compared with results from a blowdown heat transfer $200 \%$ cold leg break test which had essentially the same prerupture conditions as Test S-29-1. Also presented are results from calculations performed with the RELAP4 ${ }^{[4]}$ analytical code described in Appendix A and a special Mod-1 core model (described in Reference 2) to aid in understanding the events which took place within the core during the blowdown phase of the test.

Section II of this report presents a description of the system configuration and discusses the test plan and sequence of events which took place during Test S-29-1. Section III presents the significant test results and an evaluation of these results. Section IV provides conclusions reached from the evaluation. 


\section{EXPERIMENT DESCRIPTION}

The Semiscale Mod-1 experimental system for special Test S-29-1 is described. The topics discussed briefly are the overall system configuration and the test plan, including the pretest sequence of events.

\section{SYSTEM DESCRIPTION}

The Semiscale Mod-1 test apparatus is a high-pressure system designed to operate at typical pressurized water reactor (PWR) temperatures and pressures. The system consists of a pressure vessel with simulated reactor internals (upper plenum, core region, lower plenum, and downcomer); an intact loop with an active pump, steam generator, and pressurizer; a broken loop with a simulated steam generator, simulated pump, and pipe rupture assemblies; a pressure suppression system with a header and suppression tank; and a coolant injection system with injection pumps, accumulators, and delivery piping. The broken loop design is such as to allow the simulation of either hot or cold leg breaks. The experimental system configuration for the cold leg break test with numbered spool pieces is shown in Figure 1. Descriptions of the system components, including volumes and flow resistances and details of the measurement and data acquisition systems, are contained in Reference 5.

The core simulator in the Semiscale system consists of 40 electrically heated rods of typical PWR fuel rod diameter (0.422 in.). A cross sectional view of the vessel with the core layout is shown in Figure 2. Figure 3 illustrates the general construction of a Semiscale heater rod. The overall length of the rod is about $207 \mathrm{in}$. and the bottom of the $5.5-\mathrm{ft}$. heated section is about 142 in. below the vessel cold leg centerline as shown in Figure 4. The rods extend from the bottom of the heated section through the upper plenum and pass out through the vessel upper head. The heating element shown in Figure 3 was designed to produce an axial peaking factor of 1.58 and a normalized axial power profile as shown in Figure 5.

The core rod bundle matrix showing thermocouple locations is presented in Figure 6. As shown in this figure, the heater rods are identified within the matrix by reference to the row of letters across the top and the column of numbers down the side of the matrix. Similarly, the thermocouples are identified by the rod that they are on and by their elevation above the bottom of the heated length of the core. The thermocouple on Rod D5 at the 29-in. elevation is thus referred to as TH-D5-29, where TH means a core heater cladding lemperature, D5 refers to the rod on which the thermocouple is located, and 29 gives the thermocouple elevation in inches above the core bottom. (The arrows in Figure 6 indicate thermocouple azimuthal locations.) 


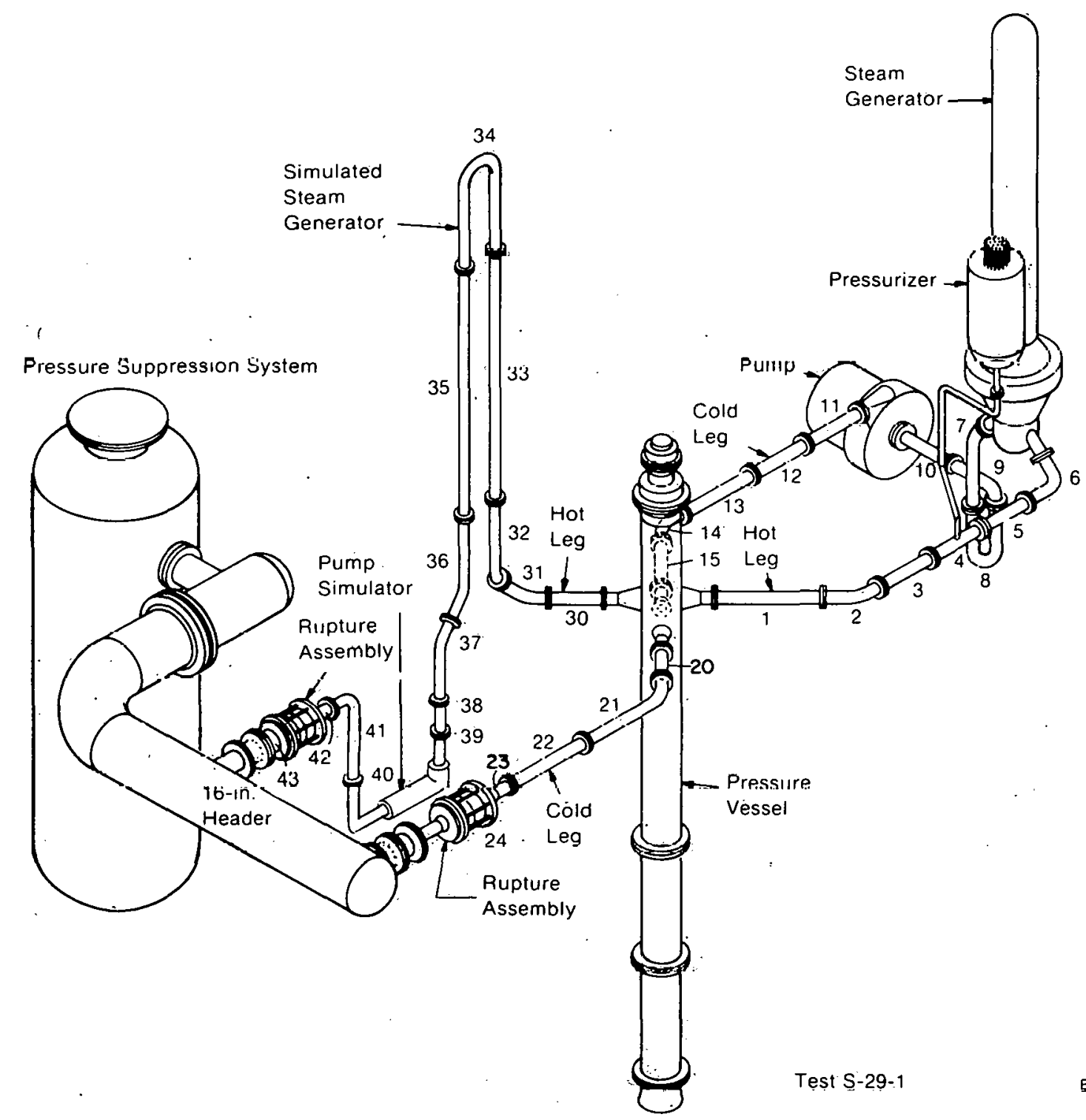

Fig. 1:Semiscale Mod-1 system configuration for Test S-29-1. 


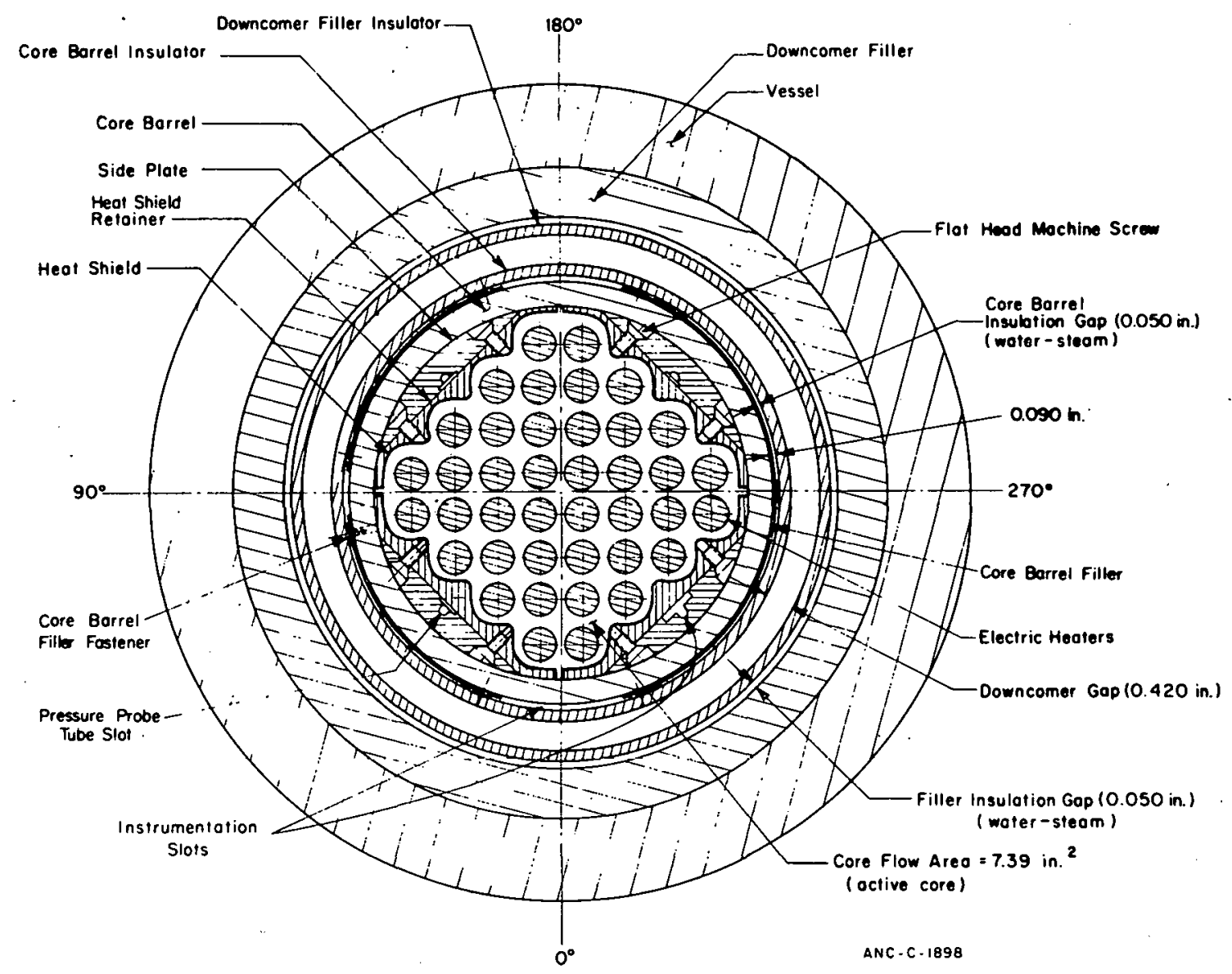

Fig. 2 Vessel cross section and core layout.

The intact loop is a volume scaled simulation of three loops of a commercial four-loop PWR and consists of primary coolant piping, a steam generator, a pressurizer, and a circulating pump. The piping is primarily 3 -in. Schedule 160 pipe. The intact loop steam generator is a tube-in-shell heat exchanger.

The blowdown loop is a volume-scaled representation of one loop of a four-loop PWR and consists of passive pump and steam generator simulators, two discharge nozzles, and two rupture assemblies which provide for a simulated double-ended offset shear break. The associated piping is primarily 2 -in. Schedule 160 stainless steel. The steam generator and pump simulator consist of piping with inserted orifices to achieve the desired hydraulic resistances. The rupture assemblies contain a converging-diverging blowdown nozzle (to provide the desired break area) and two diaphragm rupture discs.

The pressure suppression system consists of a $91.7 \mathrm{ft}^{3}$ pressure tank which is used to simulate the backpressure created by a containment building in a PWR system. The tank is maintained partially full of subcooled water, and the downcomer pipe projects below the water surface to accommodate the blowdown effluent. A 16-in. header connects the pressure suppression tank to the primary coolant system. 


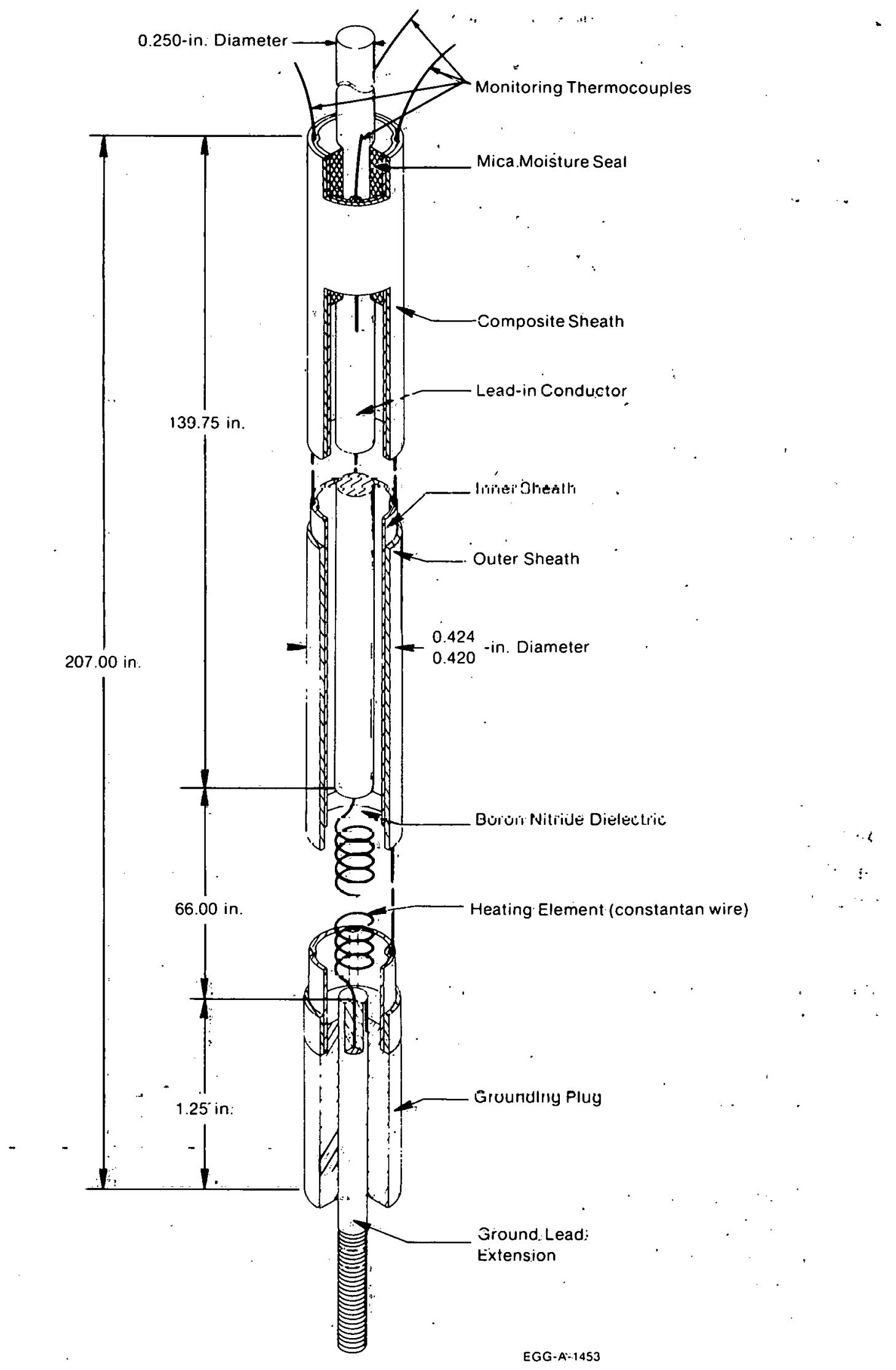

Fig. 3 Semiscale Mod-1 electric heater. rod. 


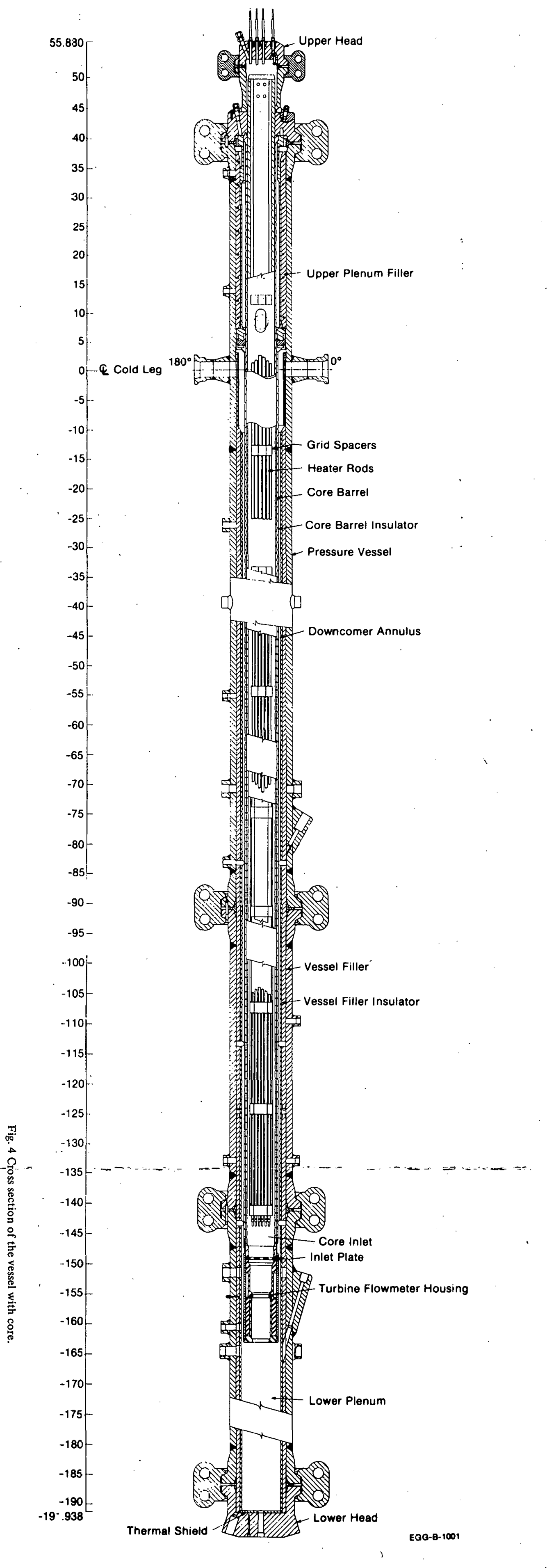




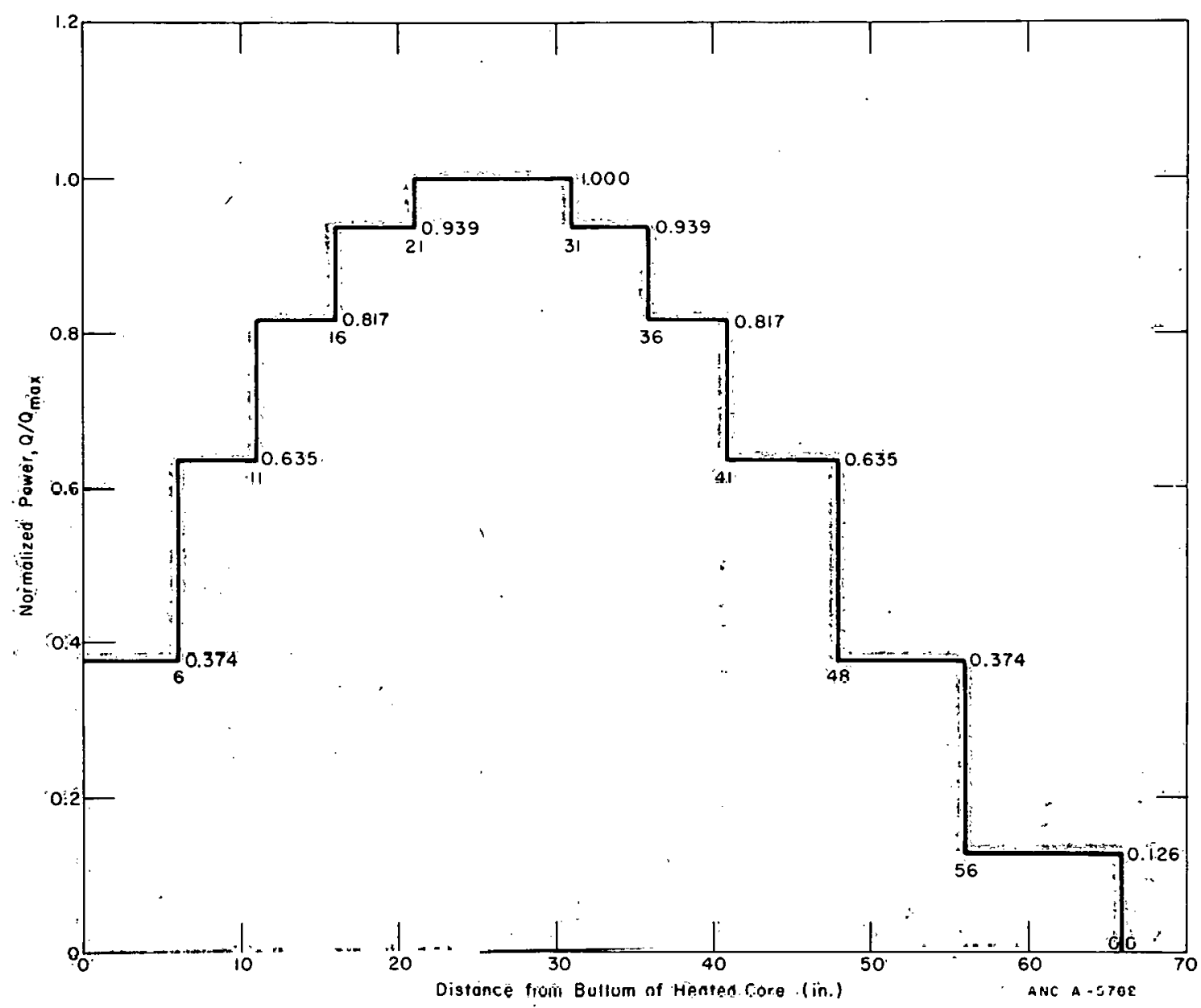

Fig. 5 Semlscale Mod-1 hẹa tẹter ròd axial oower distrihutinn .

The emergency core coolant (ECC) system for Test S-29-1 was system volume scaled to a PWR. ECC was supplied to both the intact and broken loop cold legs by means of an acluinulalur lank and low procsšure injection system (LPIS ) pumps. The break configuration was the same as a $200 \%$ double-ended cold leg break test with the exception of the vessel side break area which had about onc-half thc area assuciated willı a $200 \%$ break test. Table I lists the initial conditions and ECC parameters for Test S-29-1.

Mcasürcments takèn in the system Included: volumetric flow rates, momentum flux, density, material and fluid temperatures, pressure drops, and pressure. Volumetric flow rates were measured using a turbine flowmeter. Gamma densitometcrs were used to measure density. Thermocouples were used for the temperature measurements. The pressure and differential pressurc drop measurements were. made with calibrated pressure and difterential pressure transducers. The total expected error in each type of measurement is identified in Reference 5. 


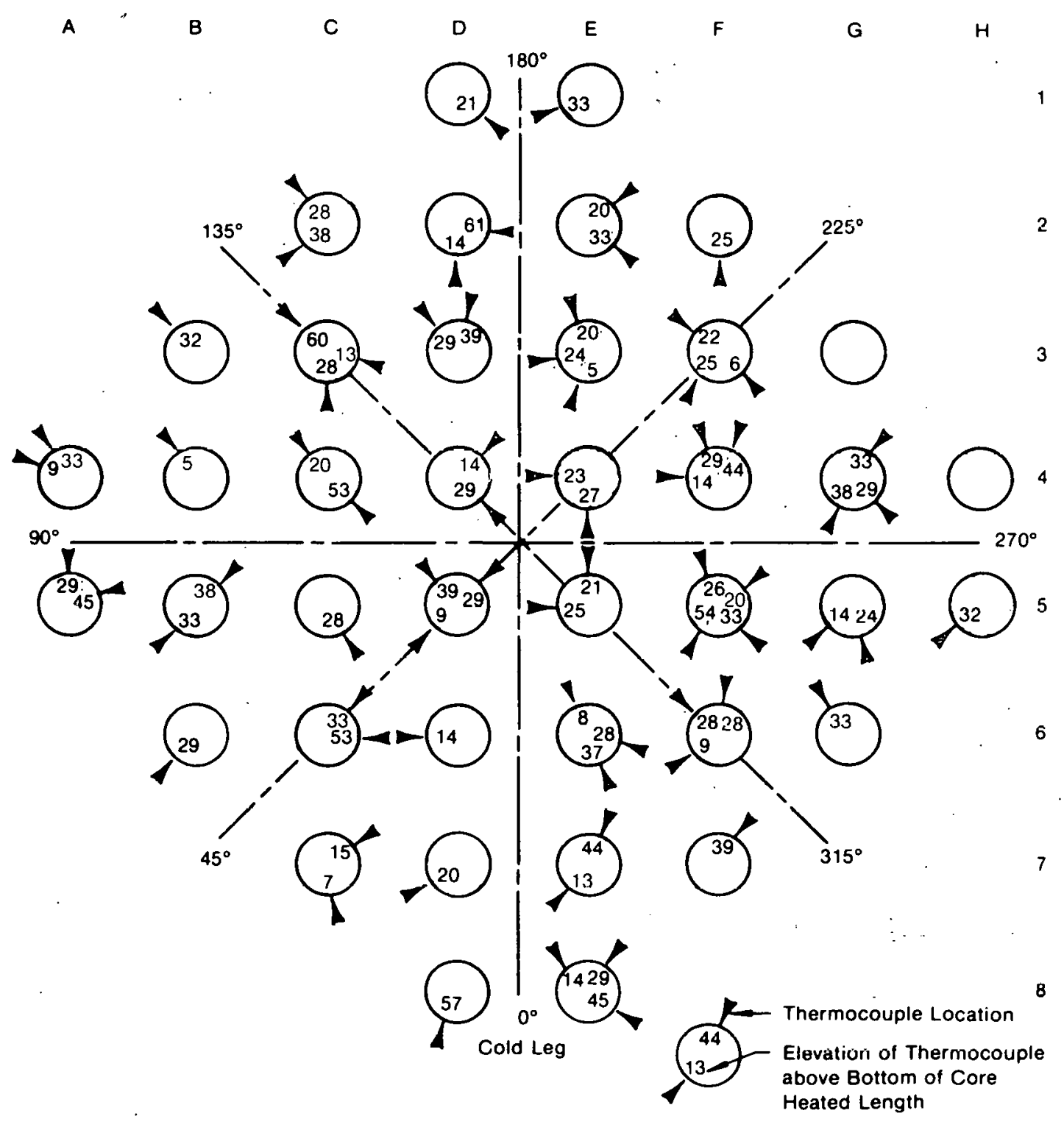

Fig. 6 Semiscale Mod-1 heater core - plan view showing instrumentation. 


\section{TABLE I}

INITIAL CONDITIONS AND ECC PARAMETERS FOR TEST S-29-1

\section{Initial Conditions}

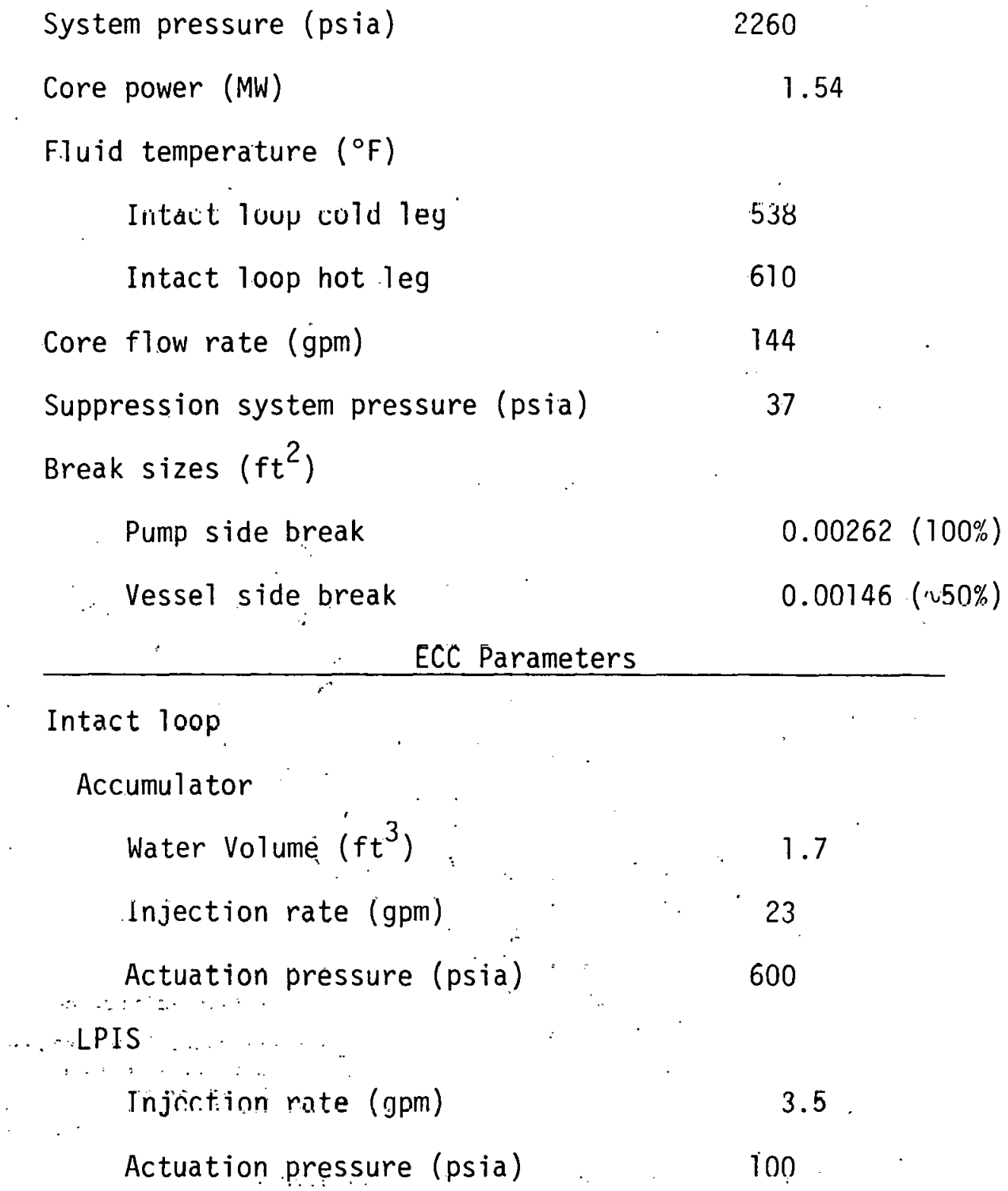

\section{Intact loop}

Accumulator 


\section{TEST PLAN}

Table I presents the initial conditions for Test S-29-1. With the exception of the vessel side break area this test was typical of other $200 \%$ cold leg break tests and was specified such that direct data comparisons between tests could be made. The ECC systems for Test S-29-1 were system volumetrically scaled to a PWR. This scaling resulted in average flow rates from the intact loop accumulator and LPIS of 23 and $3.5 \mathrm{gpm}$, respectively.

The sequence of events that was to be followed in Test S-29-1 prior to test initiation was to establish system core inlet fluid conditions at about $544^{\circ} \mathrm{F}$ and 2260 psia, to adjust the core power and flow to achieve the desired core differential temperature, and then to break the rupture discs in both the vessel inlet and outlet sides of the broken loop allowing the system fluid to flow out through two break nozzles and into a pressure suppression tank. During Test S-29-1 the resistance bulb thermocouple located in Spool 14 (RBU-14) failed, and consequently, the temperature rise across the heated core could not be properly monitored during the pretest system warmup. A posttest survey of the data indicated that the lack of adequate monitoring resulted in a core differential temperature of about $72^{\circ} \mathrm{F}$. Furthermore, the core power sequencer malfunctioned resulting in the power controller actuating about $0.5 \mathrm{sec}$ prior to rupture. The combined effect of these events produced conditions that varied somewhat from those originally designed but are not considered to have significantly influenced the test results. 


\section{TEST RESULTS}

The following sections present an evaluation of the observed Semiscale Mod-1 system response during Test S-29-1. The first section presents the general hydraulic response. Discussed in this section is the effect of the reduced break area on general system hydraulics as well as core inlet flow. Results from Test S-02-7 of the blowdown heat transfer test series, which had essentially the same prerupture conditions as Test S-29-1, are included to illustrate the effect of the break area on system response. The second section presents the core thermal response and the effect the altered core flow had on core heat transfer. Data from Test S-02-7 are again included together with analy tical model calculations to illustrate the core flow effect on core thermal response. The third section describes the general system behavior during the refill and reflood portions of Test S-29-1.

\section{GENERAL SYSTEM HYDRAULIC RESPONSE DURING}

\section{THE BLOWDOWN TRANSIENT IN TEST S-29-1}

The effect that the reduced vessel side break area had on the resulting system hydraulic response is discussed in this section. Emphasis is placed on analyses of those events which led to the resultant core flow behavior and system depressurization rate in Test S-29-1.

The influence of the reduced break area in Test S-29-1 on the early vessel side hreak mass flow rate is shown in Figure 7 by a comparison of the vessel side break mass flow rates from Têsts $\bar{S}-2 \dot{Y}-\dot{I}$ and $S-U 2-\%$. The decrease in break tlow area in Test S-29-1 caused an increase in the hydraulic resistance across the break resulting in a significant reduction in the magnitude of the mass flow rate during the subcooled portion of the blowdown transient. The transition from subcooled to saturated break mass flow (indicated in Figure 7 by the abrupt decrease in the magnitude of the mass flow rate) was delayed from $3 \mathrm{sec}$ in Test S-02-7 to $7 \mathrm{sec}$ in Test S-29-1. This longer subcooled flow period in Test S-29-1 resulted because of the different flow and pressure transients in the broken loop cold leg and in the 'vessel. Shortly after rupture in Test S-02-7, saturated core fluid traveled up the downcomer towards the inlet annulus where it mixed with subcooled flow from the intact loop cold leg. As indicated in Figure 8, the transit time was about $2.5 \mathrm{sec}$ and by $3 \mathrm{sec}$ the flow of fluid from the vessel was sufficient to raise the fluid temperature near the inlet to the broken loop cold leg to the saturation temperature corresponding to the pressure in the broken loop cold leg. In Test S-29-1, however, the vessel side break mass flow was only about half of what it was in Test S-02-7 and, therefore, the demand on fluid from the core was significantly reduced. Consequently, not only was the fluid transit time from the core to the inlet annulus increased from 2.5 to $5 \mathrm{sec}$ as indicated in Figure 9 but the magnitude of the flow from the core was reduced such that only a gradual fluid temperature rise began at about $5 \mathrm{sec}$. The rise in fluid temperature continued until the saturation temperature was reached at about $7 \mathrm{sec}$. 


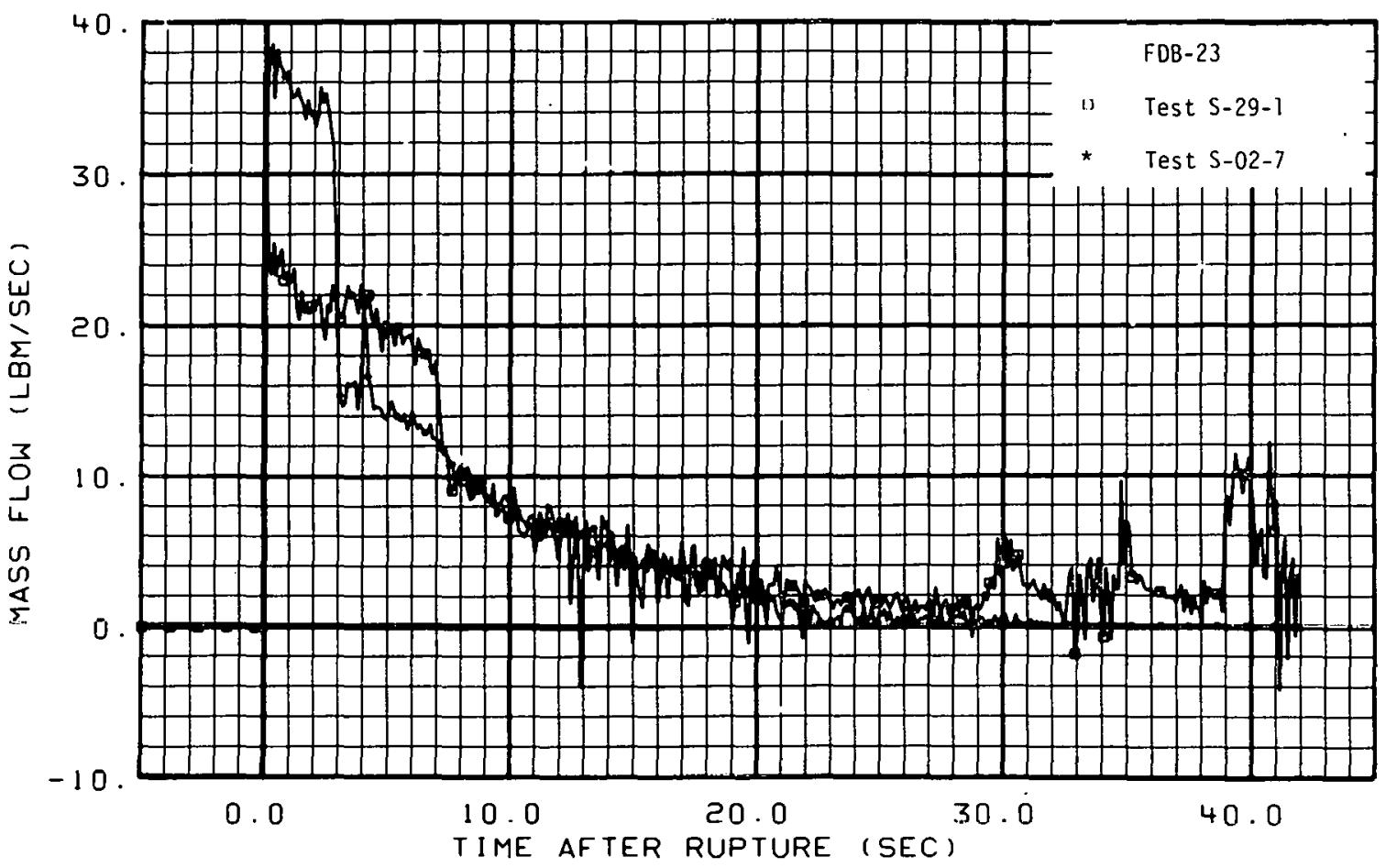

Fig. 7 Mass flow rate at the vessel side break - Tests S-29-1 and S-02-7.

The vessel side break mass flow rate in Test S-29-1 was, as in all cold leg break tests, the dominant influence on the initial core flow behavior. The differences observed between the vessel side break mass flows in Tests S-29-1 and S-02-7 are directly reflected in the respective core volumetric flows shown in Figure 10. The reduction in vessel side break flow in Test S-29-1 relative to that for Test S-02-7 placed a smaller demand on the amount of fluid flow from the core to the break. As a result, the magnitude of the core flow reversal that took place shortly after rupture in Test S-29-1 was much smaller than it was in Test S-02-7. Furthermore, as the subcooled liquid in the broken loop approached saturation, the flow from the intact loop cold leg began to supply a larger percentage of the vessel side break flow demand and by $6 \mathrm{sec}$ was supplying practically all the vessel side break flow demand. The intact loop pump head at this time was sufficient to cause lower plenum fluid to flow upward (positive direction) through the core giving rise to the high density positive core flow indicated by Figures 10 and 11. This high density positive core flow in Test S-29-1 continued for the most part until $30 \mathrm{sec}$ after rupture as indicated by the figures. The positive core flow behavior had substantial effect on the system depressurization rate and consequently the duration of the blowdown transient.

The initial system depressurization rates for Tests S-29-1 and S-02-7 are compared in Figure 12. For the first 6 to $7 \mathrm{sec}$ following rupture, the system in Test $\$-29-1$ depressurized at a slower rate than that of Test S-02-7. This trend in depressurization is reasonable in view of the magnitude of the vessel side break mass flow rates shown in Figure 7 and also in view of the magnitude of the pump side break mass flow rates shown in Figure 13. However, if the energy removal from the system following $7 \mathrm{sec}$ is estimated using the magnitudes of the 


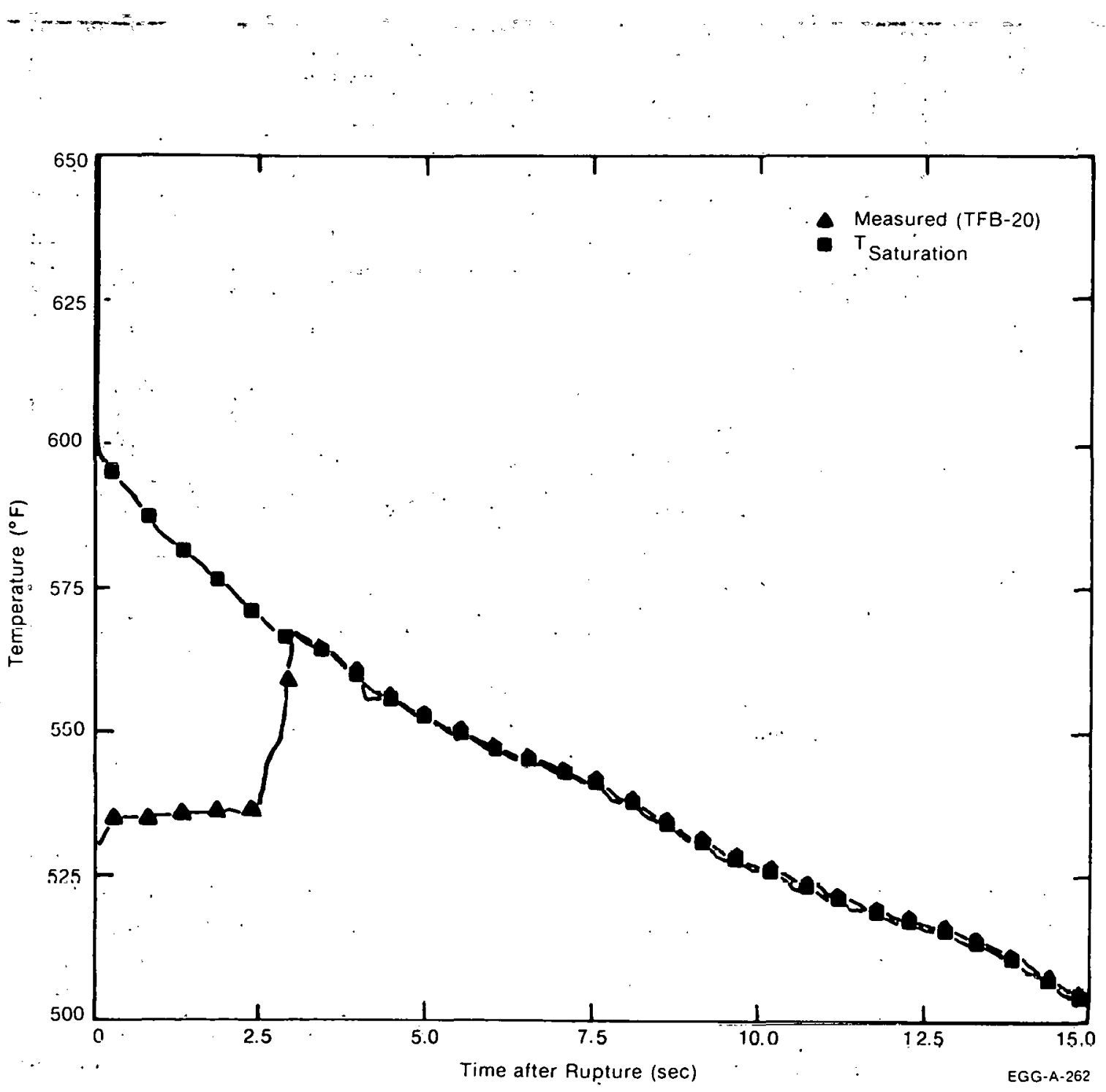

Fig. 8 Fluid temperature near the broken loop cold leg vessel inlet versus the cold leg saturation temperature - Test S-02-7.

break mass flow rates, then the data of Figures 7 and 13 indicate that the systeni in Test S-29-1 should have depressurized at a higher rate than that of Test S-02-7. The fact that such is not the case can be attributed to a higher rate of core steam generation in Test S-29-1 resulting from the high density positive core inlet flow between 6 and 30 sec after rupture as discussed previously. The higher relative system pressure in Test S-29-1 in turn helped maintain a saturated vessel side break mass flow rate similar to that in Test S-02-7 despite the differences in the break area. The consequences of the prolonged blowdown period in Test S-29-1 (discussed in Section III-3) were minimized by the high core heat transfer rates which took place during blowdown as discussed in the next section. 


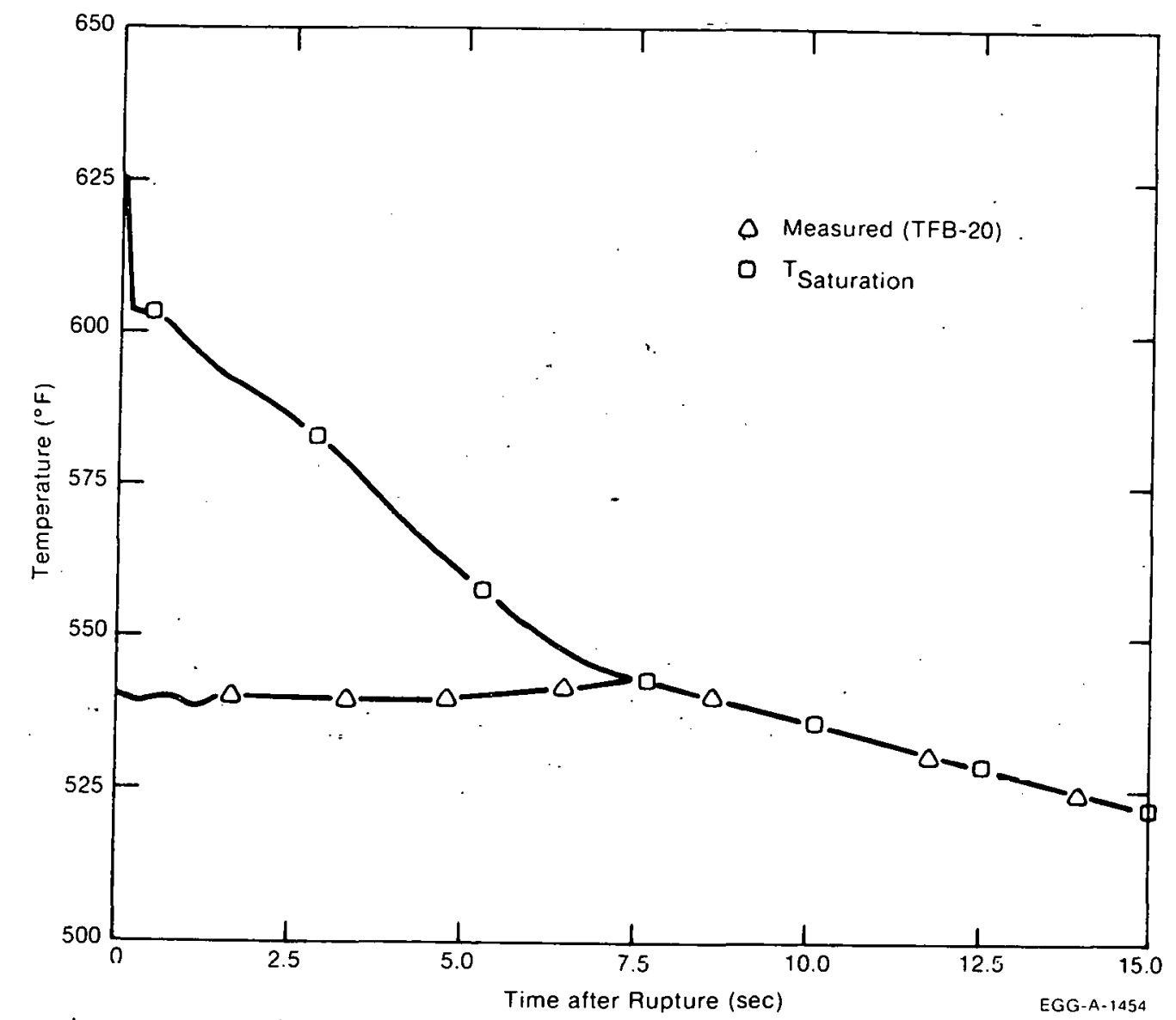

Fig. 9 Fluid temperature near the broken loop cold leg vessel inlet versus the cold leg saturation temperature - Test S-29-1.

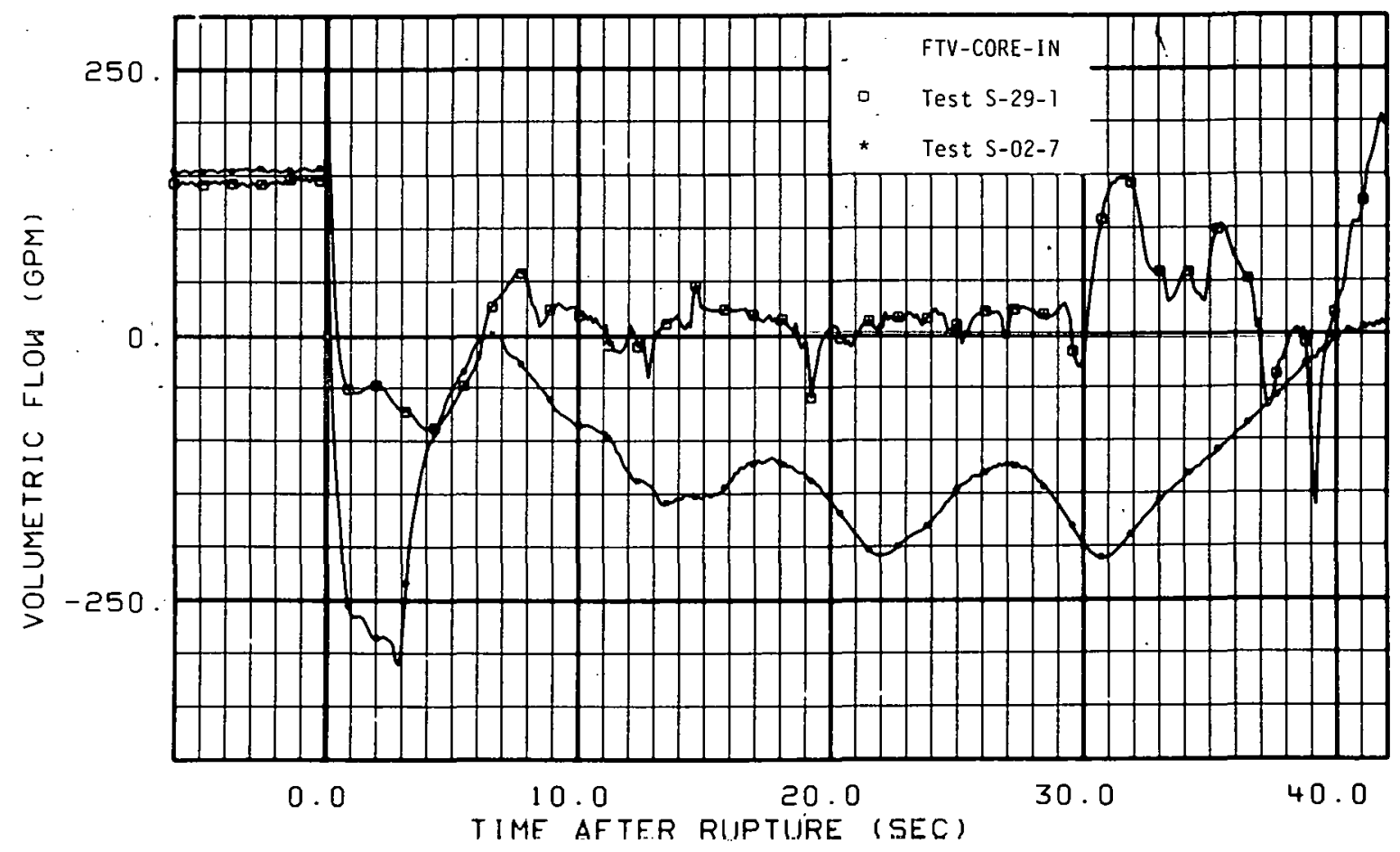

Fig. 10 Volumetric flow rate near the core inlet - Tests S-29-1 and S-02-7. 


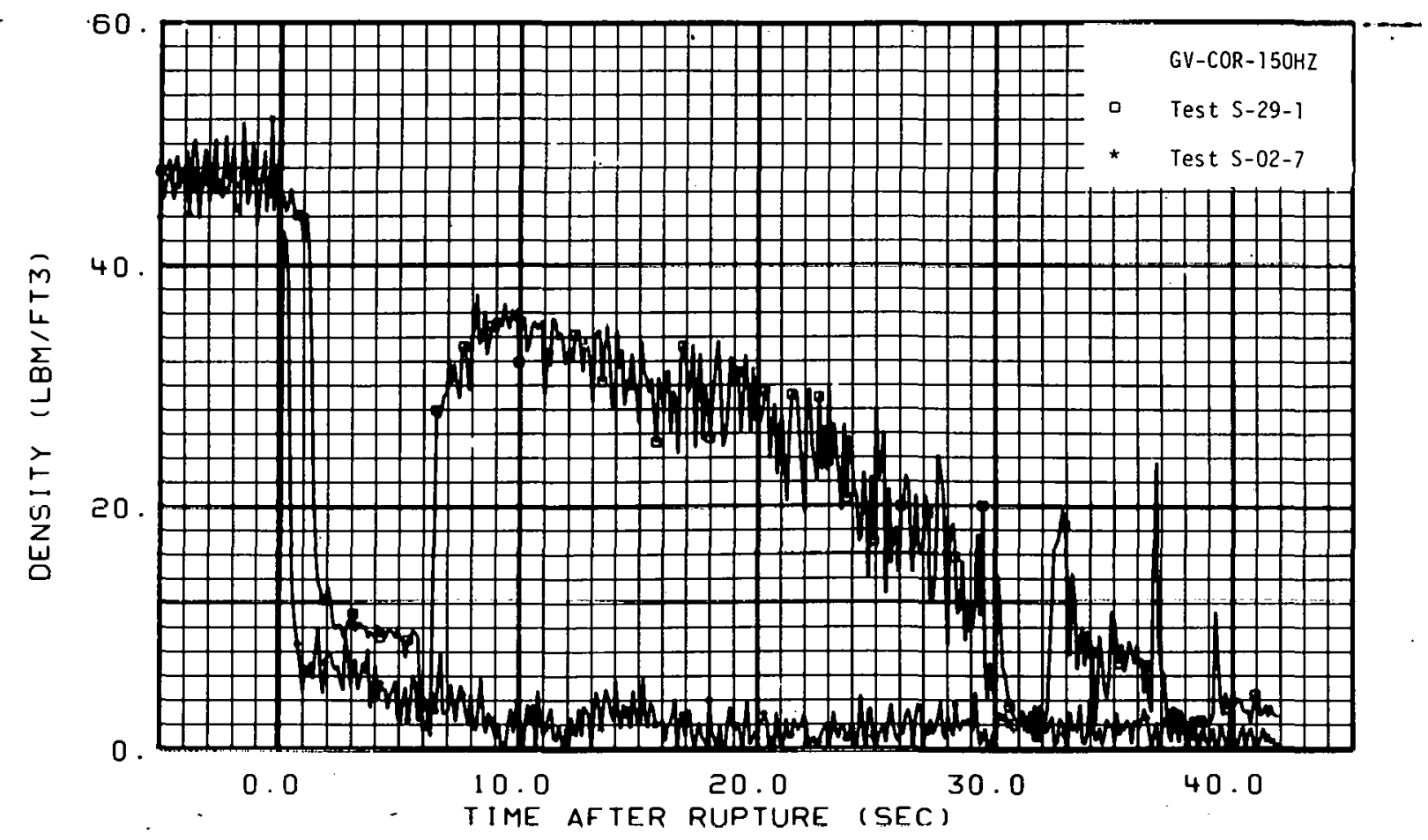

Fig. 11 Fluid density near the core inlet - Tests S-29-1 and S-02-7.

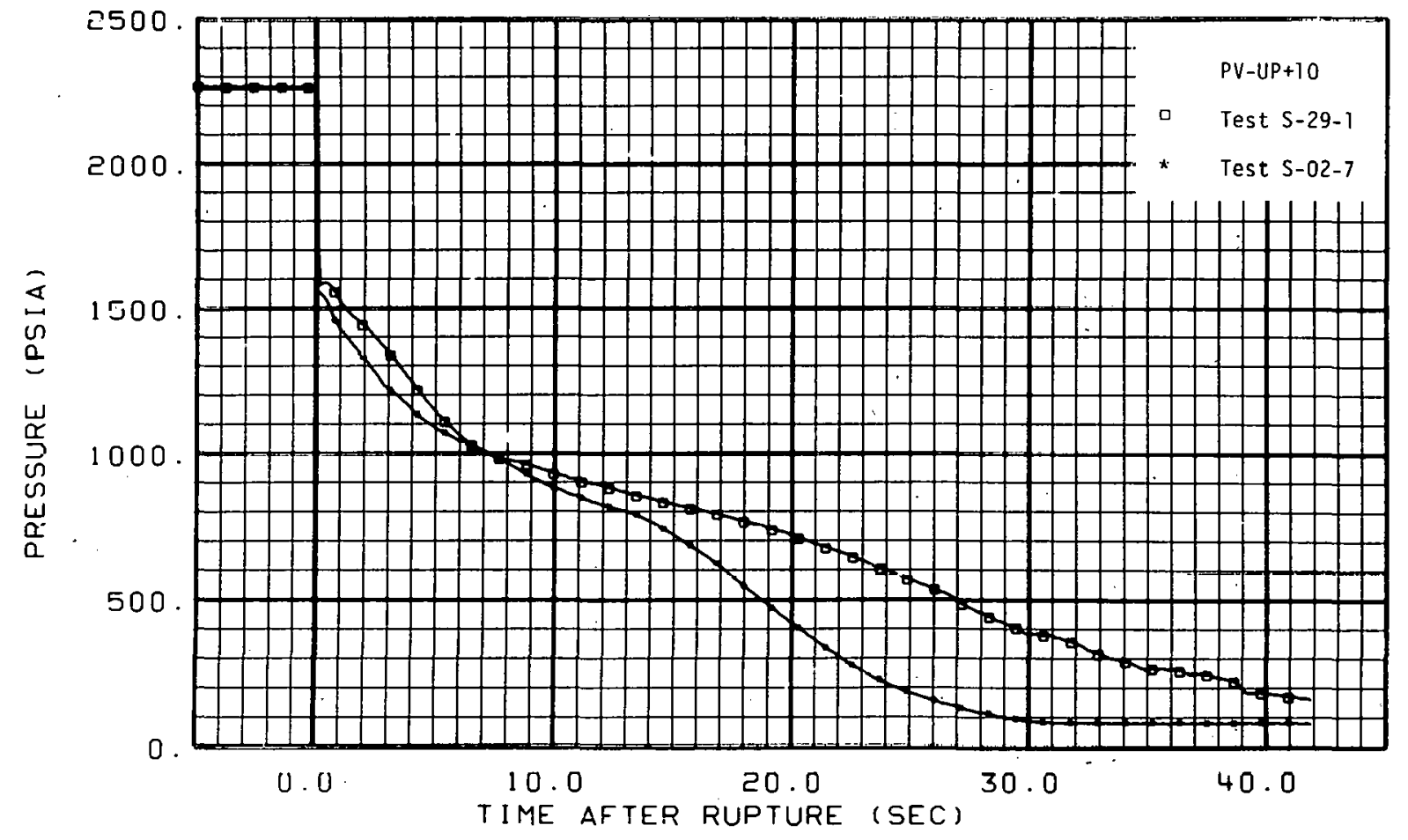

Fig. 12 Upper plenum pressure - Tests S-29-1 and S-02-7. 


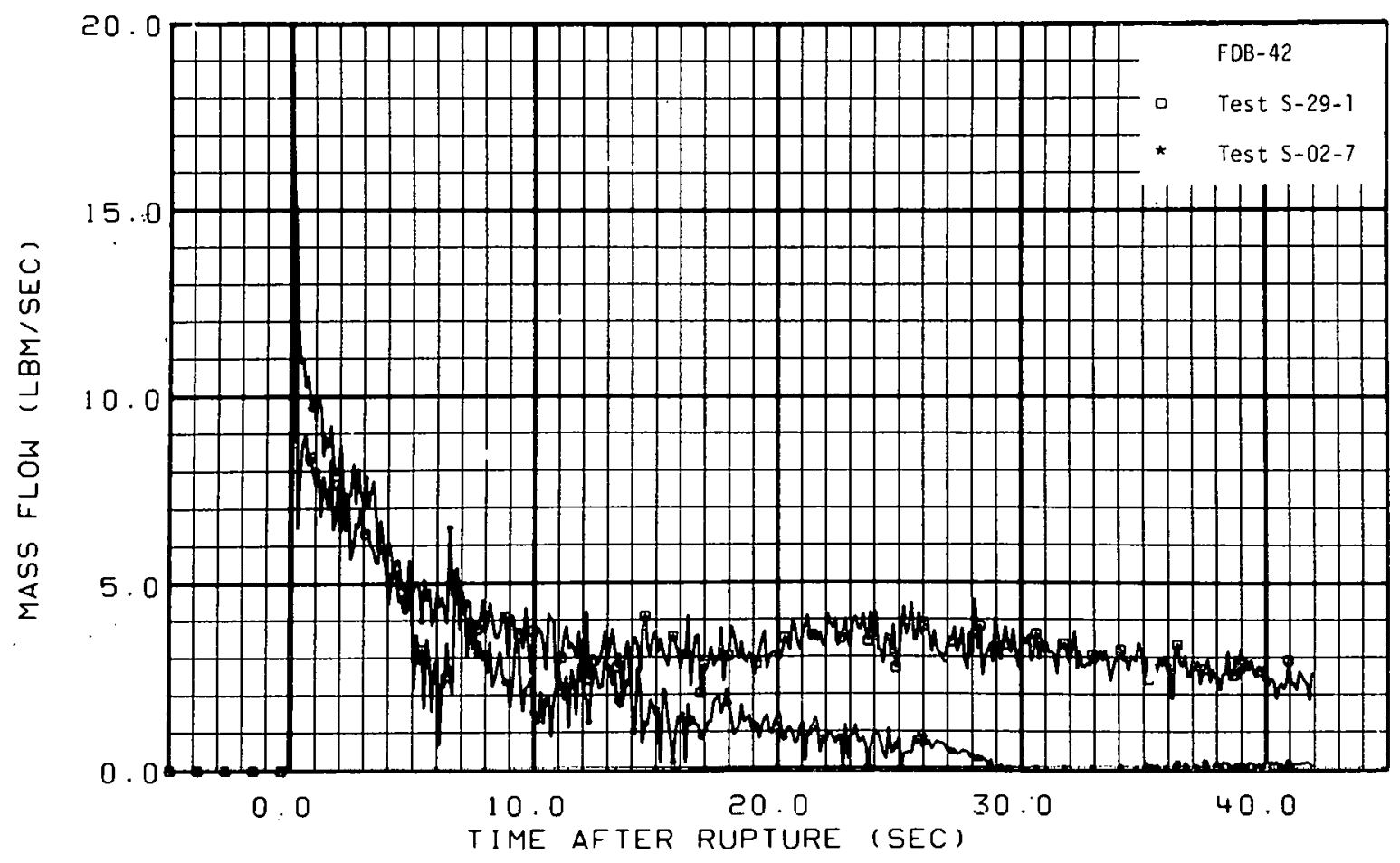

Fig. 13 Mass flow rate near the pump side break - Tests S-29-1 and S-02-7.

\section{CORE THERMAL RESPONSE}

The sensitivity of the Semiscale Mod-1 core thermal response during Test S-29-1 to core flow was evaluated through comparisons with data from Test S-02-7. Calculations obtained from the RELAP4/MOD5 Update 1 analytical system model (Appendix A) and from a special model of the Mod-1 core ${ }^{[2]}$ were also used to aid in understanding the core thermal response.

The primary objective of this test was the evaluation of the Semiscale Mod-1 early core behavior under an unprecedented core flow transient. The core flow transient in Test S-29-1 (shown in Figure 10) was established as discussed previously. A significant variable for evaluation under this flow transient is the time to rod CHF. The time of CHF is important because of the severe degradation in rod-to-fluid heat transfer that follows immediately after CHF is attained. The dependency of CHF on core flow direction was analyzed in Reference 2 which compared rod temperature responses during blowdown for both cold and hot leg break tests. The results showed that the core flow during the hot leg break test remained positive for most of the blowdown transient, that the rod temperatures during this time continued to decline, and that CHF did not occur. In the cold leg break tests, however, a core flow reversal took place shortly after rupture and the rods experienced $\mathrm{CHF}$ with a corresponding temperature rise. $\mathrm{CHF}$ at the high power zone locations normally occurred within $1 \mathrm{sec}$ after rupture. The sensitivity of the Mod-1 CHF to a change in the magnitude of the immediate core flow reversal, however, was one objective of this test and is illustrated in Figure 14. This figure shows a short term rod temperature response at the same high power zone location in Tests S-29-1 and S-02-7. The data show 


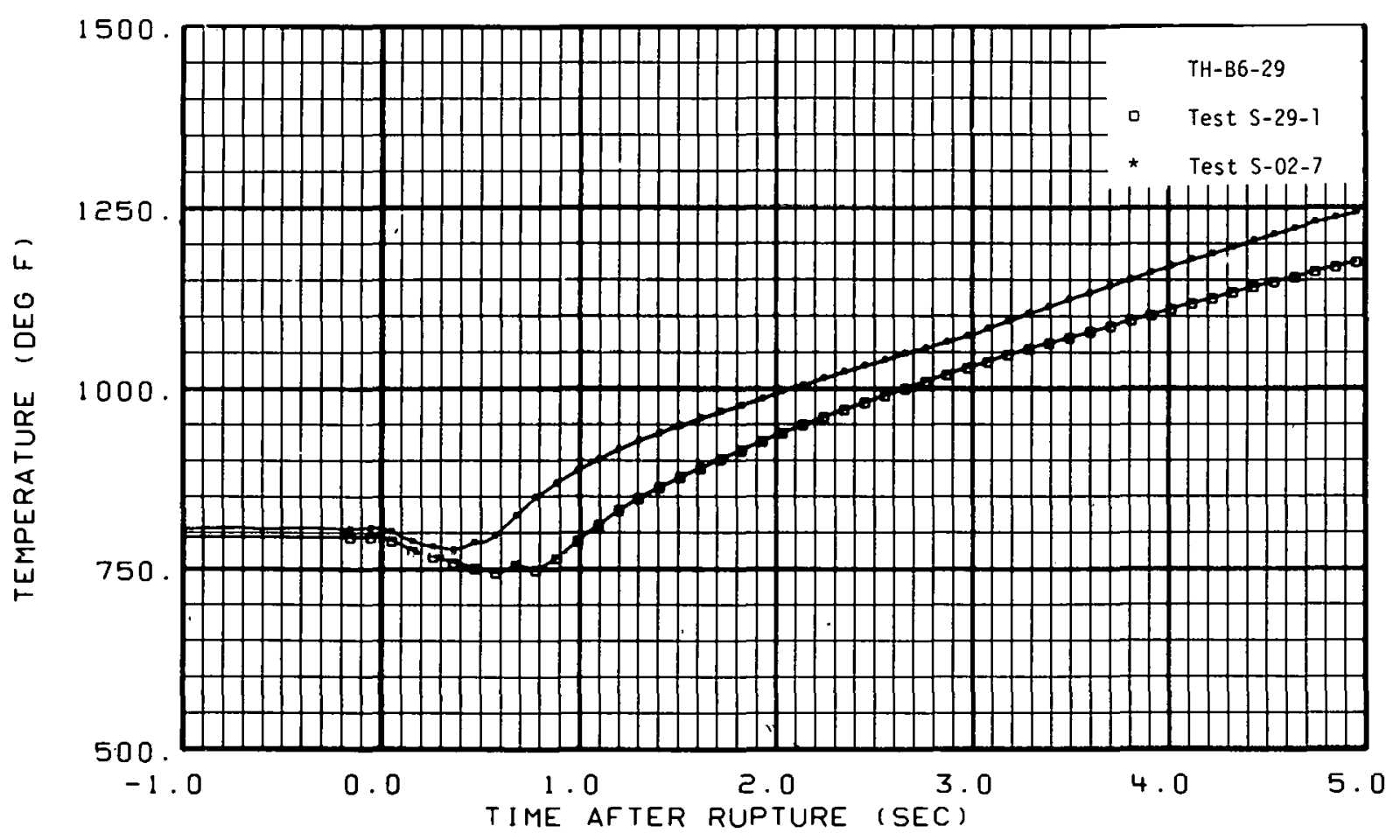

Fig. 14 Cladding temperature at the 29-in. elevation on Rod B6 (-1 to 5 seconds) - Tests S-29-1 and S-02-7.

the time to CHF was less than $1 \mathrm{sec}$ in both tests. Although an increase of 0.3 to $0.4 \mathrm{sec}$ in time to CHF occurred for Test S-29-1 relative to Test S-02-7, this difference is small in relation to the substantial differences in core flows that existed between the two tests. In conclusion, the time to CHF for the Semiscale Mod-1 core in Test S-29-1 appeared to be insensitive to the reduced initial core flow reversal.

Similarities in the rate of change of the rod temperature response after CHF. (Figure 14) indicate that heat transfer from the heater rod to the fluid was essentially the same during the first 3 to $4 \mathrm{sec}$ following CHF in both tests. However, as shown in. Figure 15, starting about $5 \mathrm{sec}$ following $\mathrm{CHF}$, a temperature measurement at a 9-in. rod elevation for Test S-29-1 began to indicate better rod-to-fluid heat transfer than was observed during Test S-02-7. This trend in better rod-to-fluid heat transfer in Test S-29-1 continued to about $9 \mathrm{sec}$ after rupture at which time the temperature measurement at this elevation showed a substantial drop in rod temperature over a relatively short period of time. This type of rod temperature response was recorded at elevations as high as the 21-in. core elevation by $20 \mathrm{sec}$ after rupture and indicated the advancement up the core of a liquid quench front similar to that which would occur in a core reflood situation. The core reflood behavior at this time began at the onset of the high density positive core flow discussed previously. As steam was generated in the lower portion of the core, it rose and cooled the rod elevations preceding the quench front. Figure 16 shows an extended plot of the data from Figure 14 and indicates that, although the quench front did not reach this core elevation, the rod temperature began indicating better rod-to-fluid heat transfer in Test S-29-1 shortly after the quent front entered the core. 


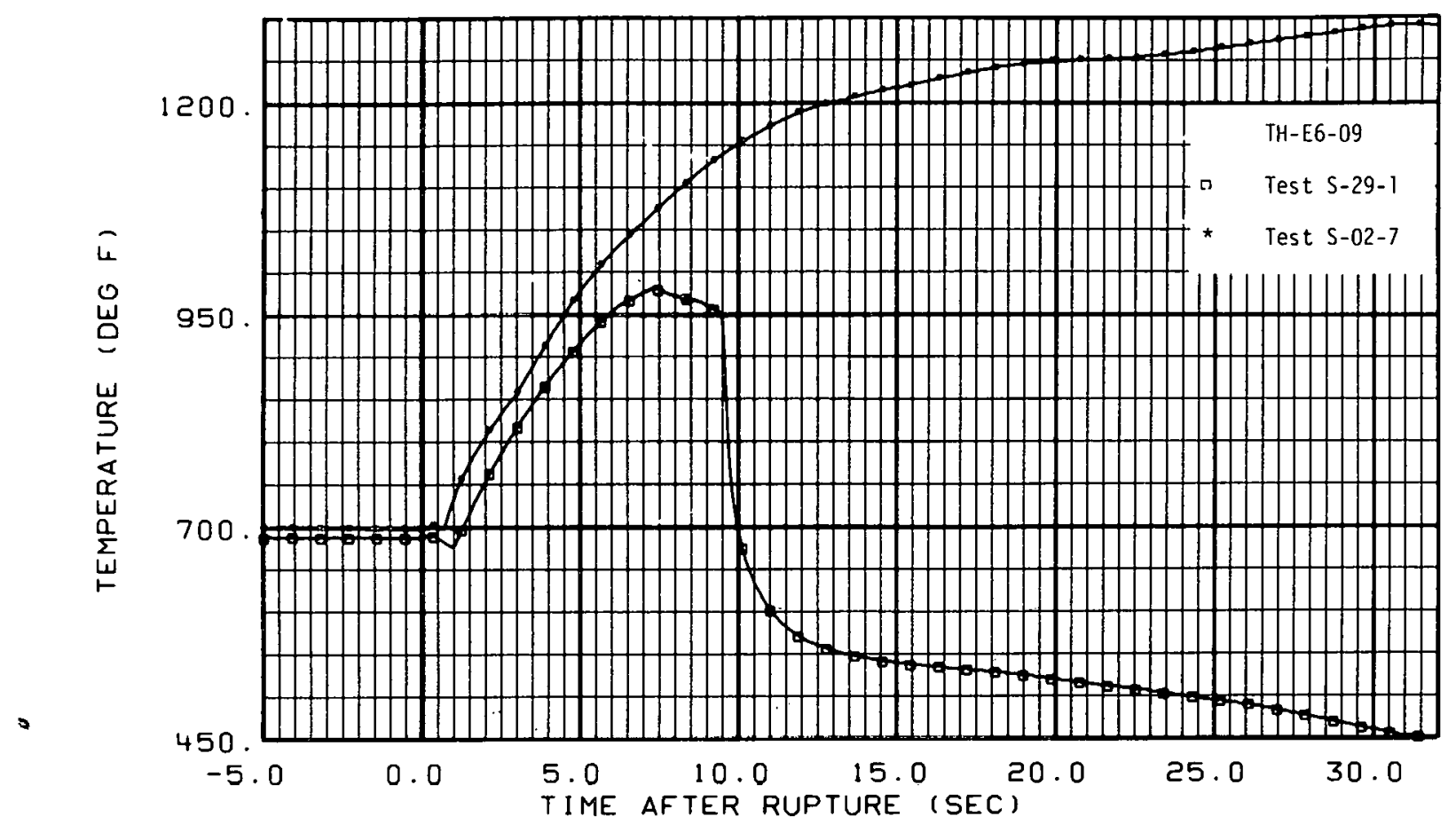

Fig. 15 Cladding temperature at the 9-in. elevation on Rod E6 - Tests S-29-1 and S-02-7.

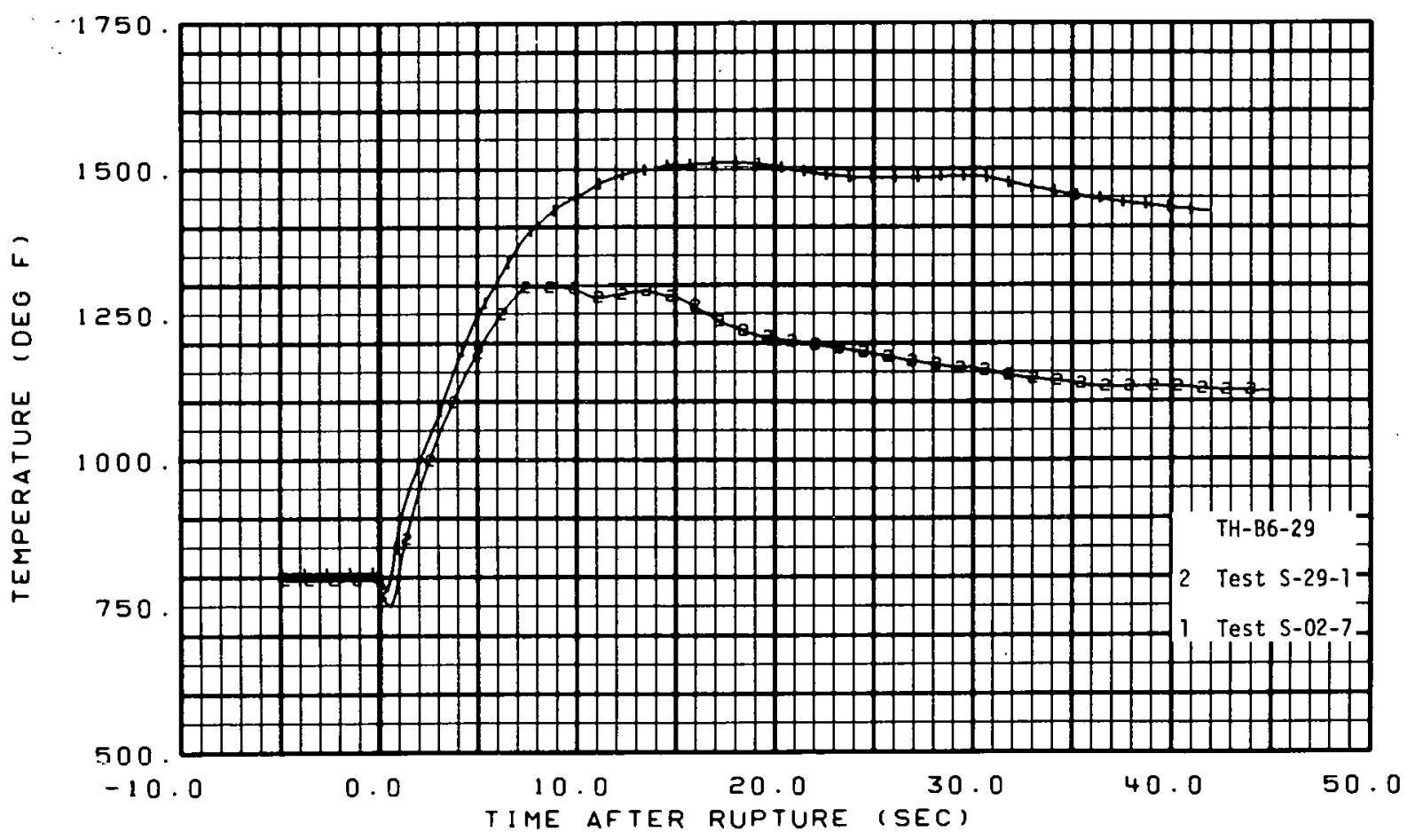

Fig. 16 Cladding temperature at the 29-in. elevation on Rod B6 (-6 to 45 seconds) - Tests S-29-1 and S-02-7. 
Posttest RELAP4 (Appendix A) calculations were performed to aid in understanding the heat transfer phenomena taking place in Test S-29-1. Figures 17 and 18 show that the calculated core inlet mass flow and core inlet density were in reasonable agreement with the data yet the temperature response at the high power zone location shown in Figure 19 was substantially overpredicted after about $8 \mathrm{sec}$. This overpredicted temperature after about $8 \mathrm{sec}$ shown in this figure was anticipated because the RELAP 4 analytical model is based on homogeneous fluid flow assumptions and not programmed to calculate core response when the nonhomogeneous flow regime typical of reflood situation is present. Furthermore, when a calculation was made using the special core model discussed in Reference 2 with a somewhat more extensive core nodalization scheme as shown in Figure 20 and with boundary conditions at the core inlet and outlet taken directly from test data, the RELAP4 homogeneous model was unable to simulate the rod thermal response exhibited by the data in Test S-29-1. Consequently, the mechanism which caused the increase in rod-to-fluid heat transfer at those elevations above the 21 -in. core elevation (final blowdown quench front elevation) was not apparent from those calculations pertormed. An additional calculation was conducted using the special Semiscale Mod-1 core model with the boundary conditions presented in Table II. Although the specification of constant core inlet enthalpy conducive to steam presented in this table was not a reflection of the measured core inlet fluid condition, the results of the calculation shown in Figure 21 illustrate that a high steam flow in the core is one mechanism which will produce a calculated trend in rod temperature similar to that obtained from the data of Test S-29-1.

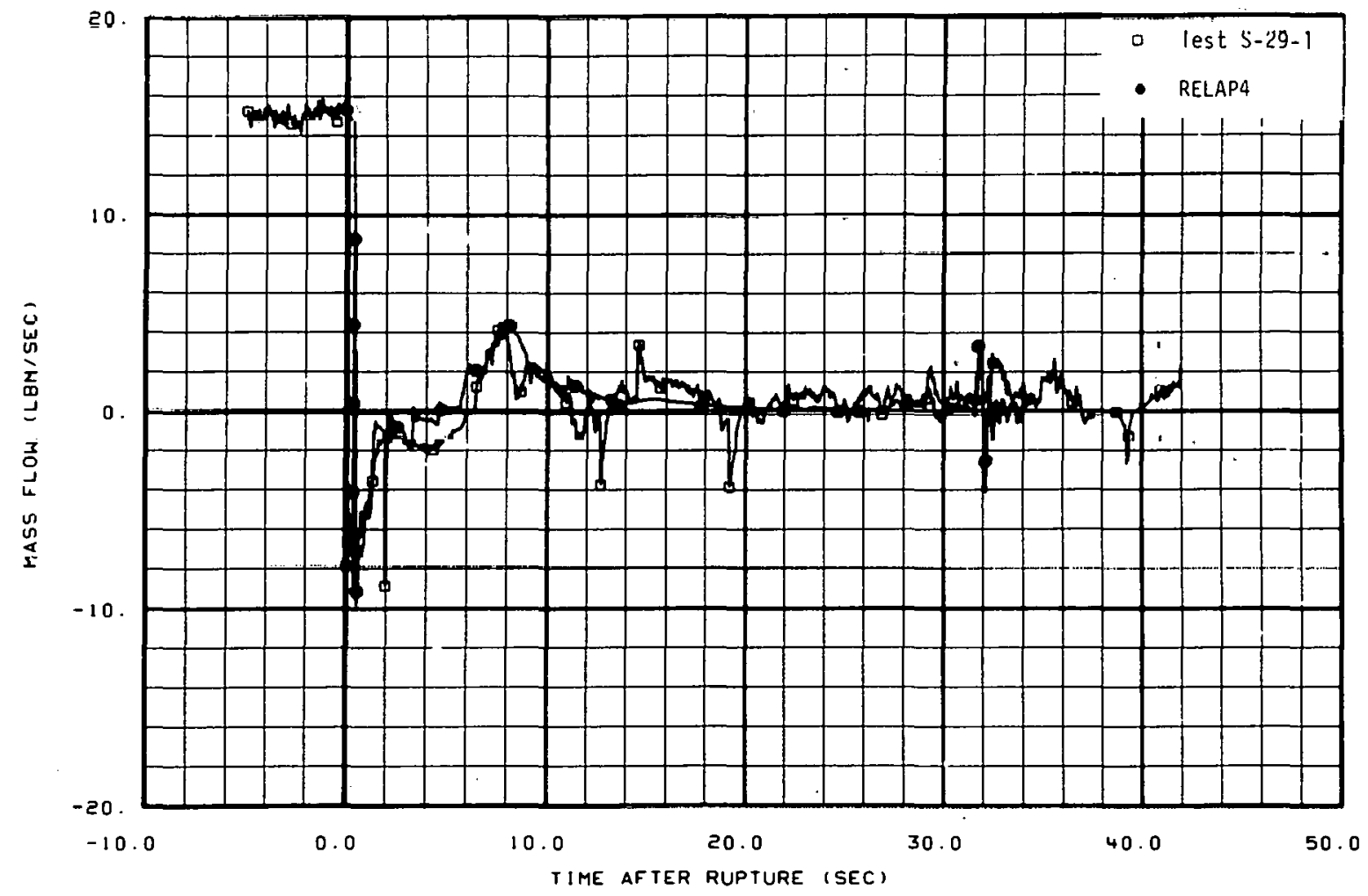

Fig. 17 Mass flow rate near the core inlet - Test S-29-1 and RELAP4 calculation. 


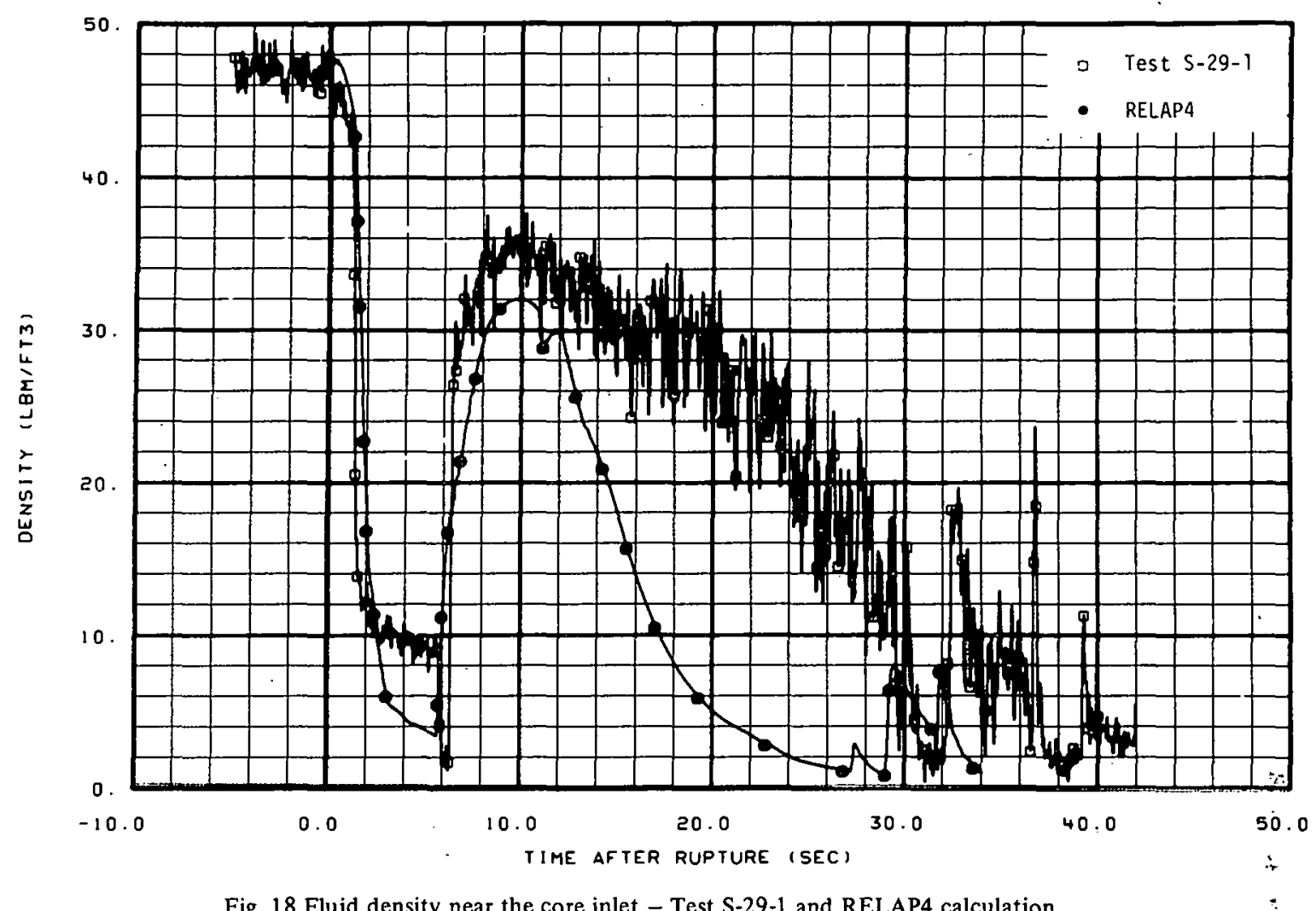

Fig. 18 Fluid density near the core inlet - Test S-29-1 and RELAP4 calculation.

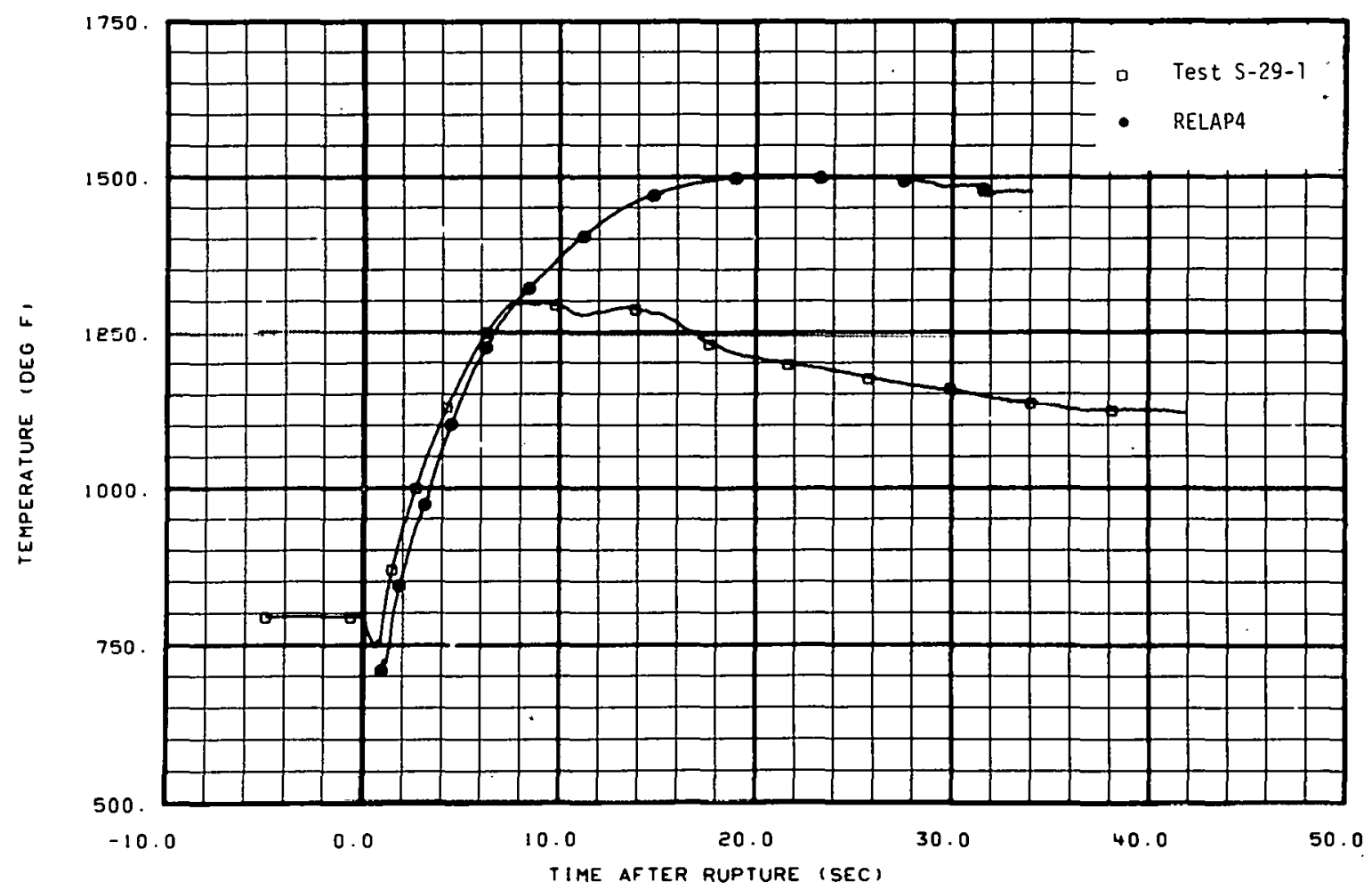

Fig. 19 Cladding temperature at the 29-in. elevalion on Rud BG - Test S-29-1 and RELAP4 calculation. 


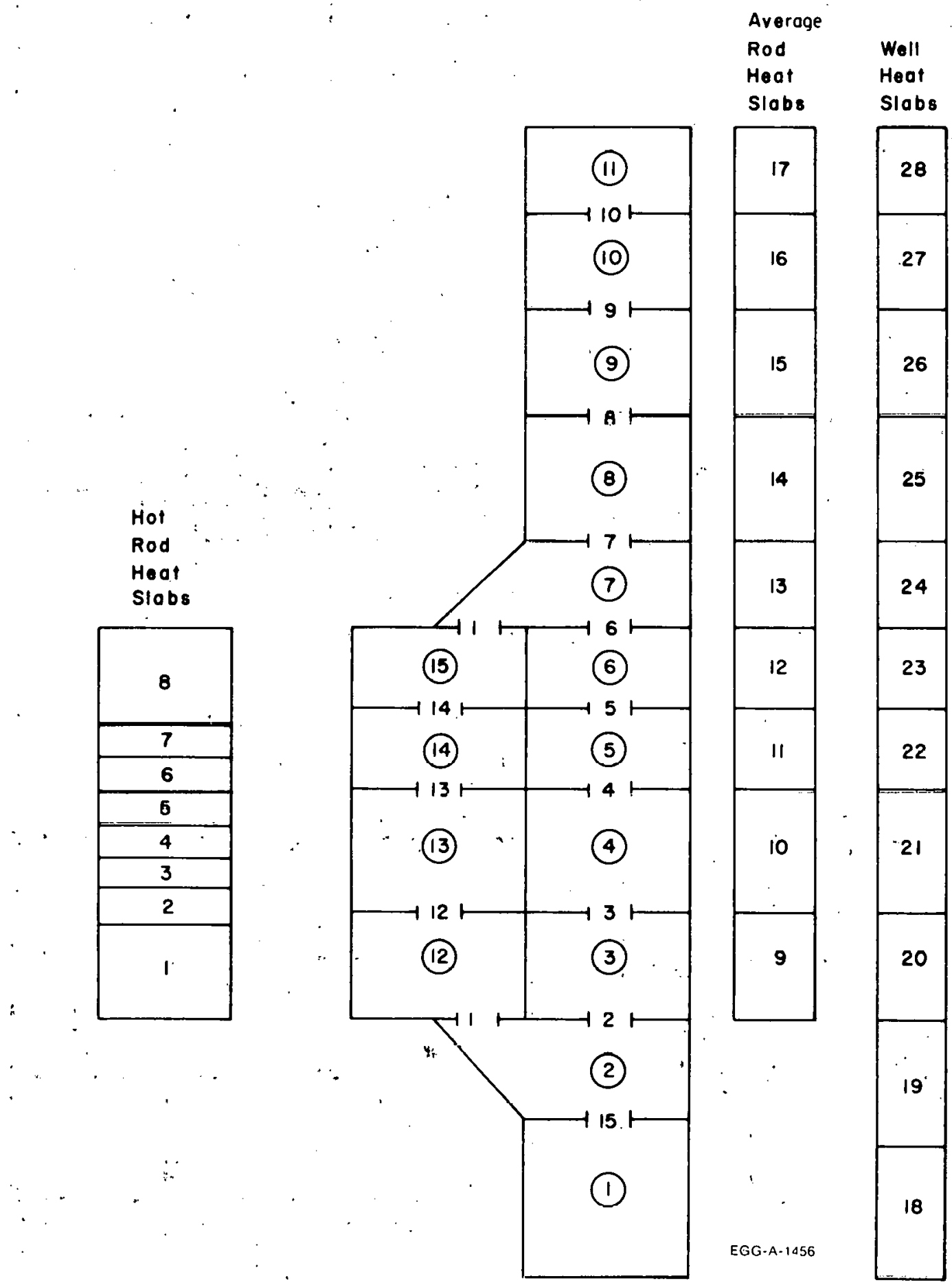

. $\quad$. Fig. 20 Semiscale special core model nodalization diagram. 
TABLE II

DESCRIPTION OF BOUNDARY CONDITIONS AND OPTIONS *

USED IN TEST S-29-1 CORE MODEL

Core inlet flow -- specified with data from the turbine flowmeter and drag disc located near the core inlet.

Core inlet fluid enthalpy -- specified constant at $1200 \mathrm{Btu} / \mathrm{lbm}$.

Pressure -- upper plenum pressure specified as a function of time using data from the pressure tranisducer located in the upper plenum.

Quality -- upper plenum quality specified as a function of time using data from the upper plenum pressure transducer and the gamma densitometer located near the broken loop vessel outlet.

Heat transfer -- standard RELAP4/MOD-5 heat transfer package used. Groeneveld 5.9 correlation used for flow film boiling.

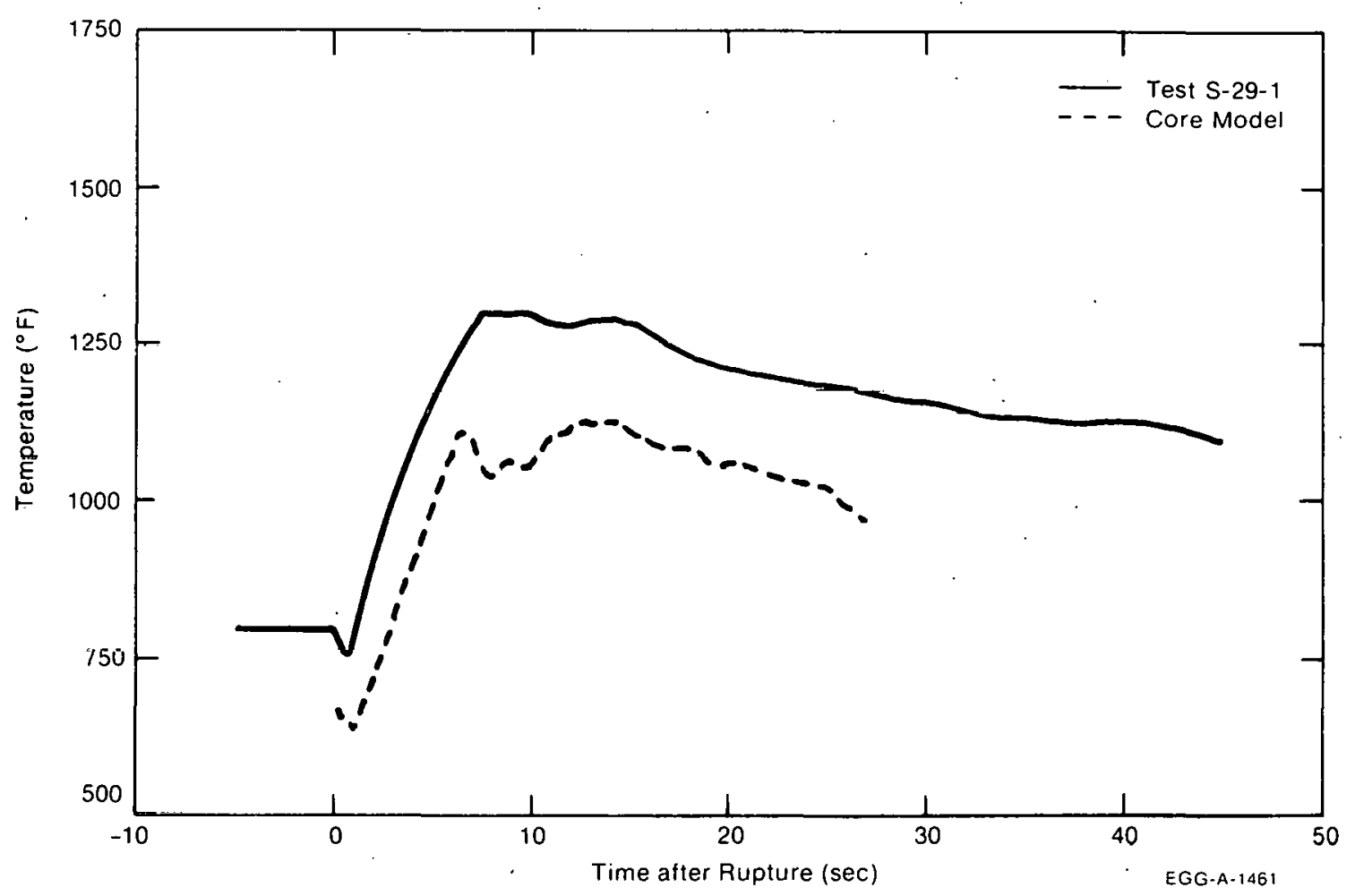

Fig. 21 Clådding temperature in the rod high power zone - special core model calculation. 
In summary, the post-CHF data obtained during the blowdown transient in Test S-29-1 showed the advancement of a liquid quench front to the 21 -in: core elevation. The steam generation in the core was sufficient to initiate temperature declines on rod surfaces preceding the quench front.' The RELAP4 system model did not accurately calculate the increase in rod-to-fluid heat transfer after the core flow returned to the positive direction because a nonhomogeneous flow condition, typical of a reflood situation, was present. This reflood type behavior during blowdown in Test S-29-1 and the high core heat transfer rates associated with it had not been witnessed in previous blowdown tests (200\% cold leg breaks) and is a direct result of changes in core inlet flow and density which were caused by the reduced vessel side break area.

\section{REFILL AND REFLOOD BEHAVIOR}

The observed Semiscale Mod-1 system response during the refill and reflood phases of Test S-29-1 is presented in this section. Discussion of the results is directed toward the effect of the prolonged blowdown period in Test S-29-1 on the ECC system response and the effect the core response during blowdown had on the core response during reflood.

The relative system depressurization rates in Tests S-29-1 and S-02-7 were discussed in Section III-1 and illustrated in Figure 12. In Test S-02-7, as in all previous blowdown tests (200\% cold leg breaks), the Mod-1 system had depressurized to the simulated containment pressure by 30 to $40 \mathrm{sec}$ after rupture. However, in Test S-29-1 the system pressure was still about 120 psia above the simulated containment pressure (about 35 psia) at $42 \mathrm{sec}$ following rupture (Figure 12). The time the simulated containment pressure is reached, is an important variable in establishing the time ECC begins flowing into the lower plenum. Past analyses [6] have shown that as the system pressure reaches the simulated conlaimment pressure, the high velocity upward flow of steam in the downcomer (termed countercurrent flow) diminishes and the ECC is no longer restricted from flowing down the downcomer. The downcomer hot wall delay time then begins, followed within 10 to $15 \mathrm{sec}$ by the initiation of lower plenum refill and shortly afterwards by core reflood. The consequences of the prolonged blowdown period during Test S-29-1 was that the injected ECC water was restricted from entering the lower plenum and core for an extended period of time and, as a result, more ECC water bypassed the downcomer and flowed out the cold leg break. This effect is illustrated in Figure 22 which shows the system pressure and fluid velocity in the downcomer and indicates, for the most part, a high upward flow of fluid in the downcomer until about $58 \mathrm{sec}$ after rupture. The indication from the sudden increase in lower plenum density shown in Figure 23 at $58 \mathrm{sec}$, however, is that the lower plenum refill began prior to the system having reached the simulated containment pressure. This seemingly contradictory behavior (relative to previous analysis) is attributed to the initiation of high velocity nitrogen flow from the intact loop accumulator as indicated by the sudden increase in accumulator volumetric flow at $57 \mathrm{sec}$ as shown in Figure 24. The initiation of nitrogen flow from from the accumulator started a pressure rise in the intact loop which was sufficient to overcome the upward flow of steam in the downcomer and thus push the 


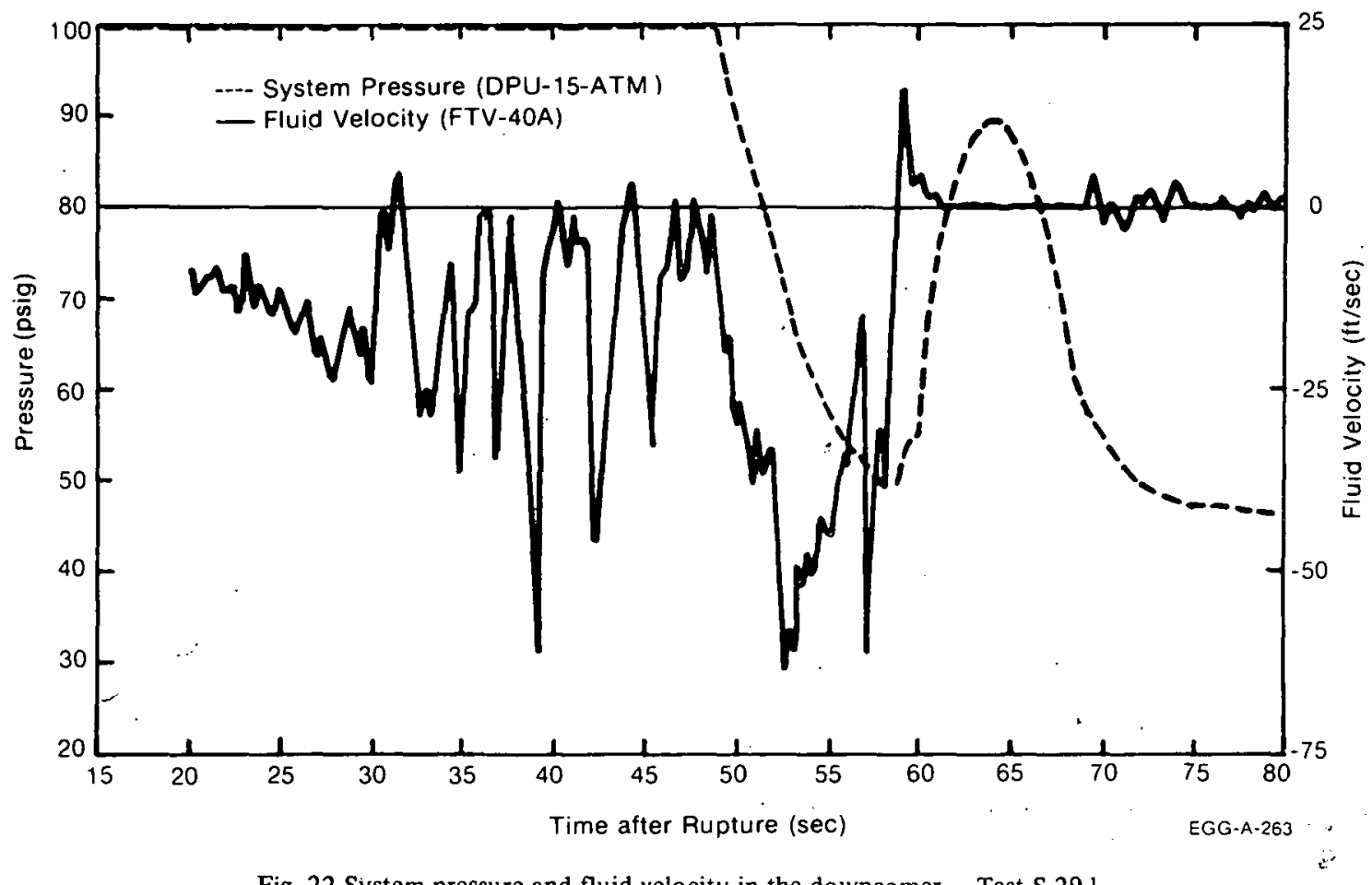

Fig. 22 System pressure and fluid velocity in the downcomer - Test S-29-1.

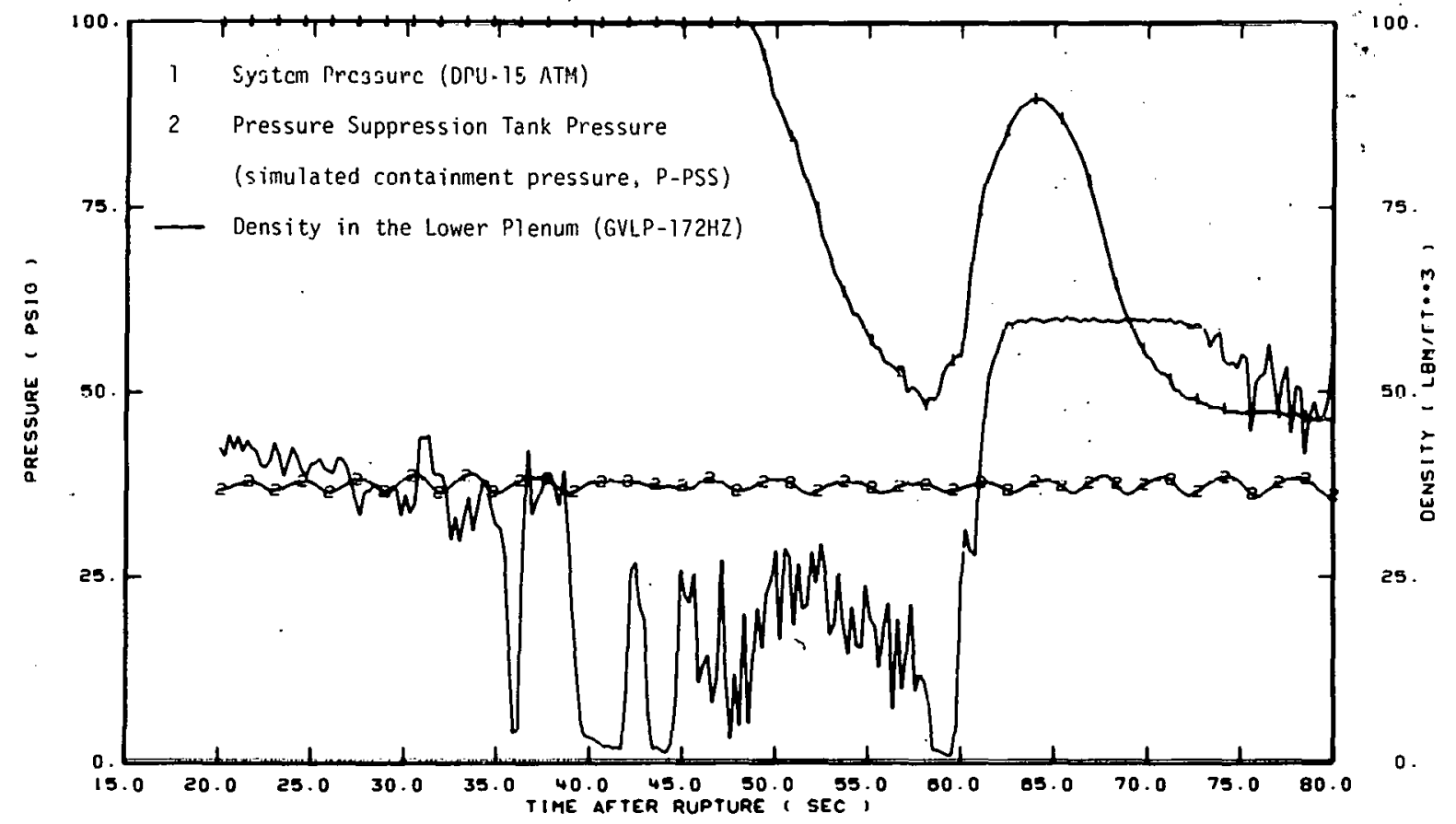

Fig. 23 System pressure versus pressure suppression tank pressure, and lower plenum density (172 in. below cold leg centerline) - Test S-29-1. 


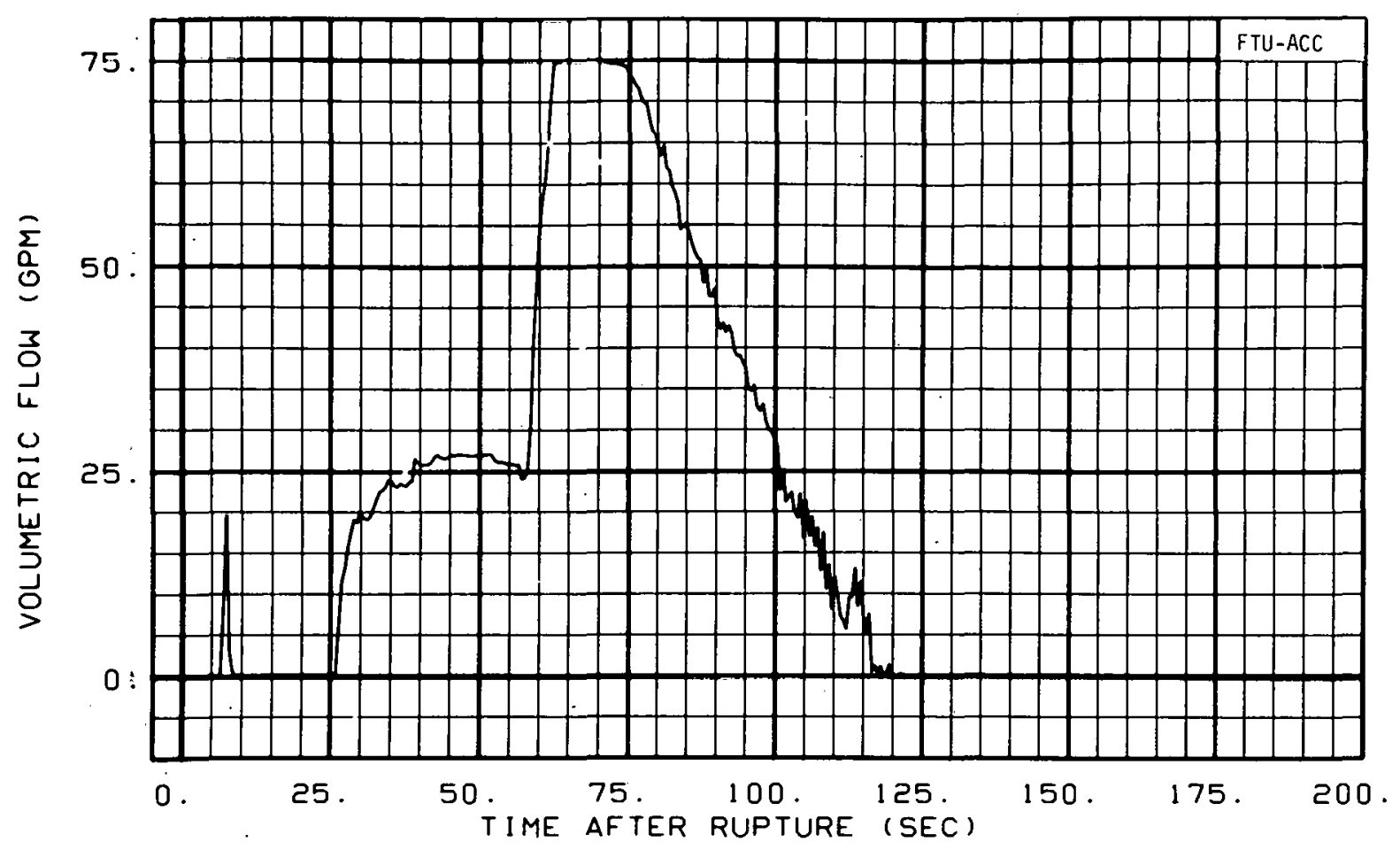

Fig. 24 Volumetric flow rate in the intact loop accumulator line - Test S-29-1.

remaining liquid in the cold leg and inlet annulus into the lower plenum. The significance of the nitrogen-initiated lower plenum refill phenomena is that the accumulator was depleted of water and, therefore, contributed little to the reflood process in Test S-29-1.

The system pressure rise in Tcst S-29-1, bcginning with the onset of the nitrogen flow from the intact loop accumulator, is postulated to be the result of the existence of a liquid plug near the ECC injection point. Prior to nitrogen injection, a high rate of steam condensation was taking place at the upstream face of the subcooled liquid plug. However, the injection of the noncondensible nitrogen gas eliminated most, if not all, of the condensation process and consequently, the liquid plug offered only an inertial resistance to flow in the intact and broken loop cold legs. This resistance to llow resulted in an increase in system pressure from the time nitrogen flow started until the time the plug was passed out the break.

The behavior of the core during blowdown in Test S-29-1 had a significant impact on the resulting core thermal response during reflood. As discussed in Section III-1, a quench front reached the 21 -in. core elevation during the blowdown portion of the test. This behavior produced a core temperature profile prior to reflood as shown in Figure 25. The low rod temperatures at, and below, the 21 -in. core elevation resulted in a rapid advancement of the reflood quench front up to the 21-in. core elevation. This rapid advancement is illustrated by Figure 26 which shows the core inlet density and indicates core reflood began at about $71 \mathrm{sec}$ and by Figure 27, which indicates the 21 -in. elevation on Rod E5, had queniched by $88 \mathrm{sec}$. This $17 \mathrm{sec}$ period corresponds to an average flooding rate 


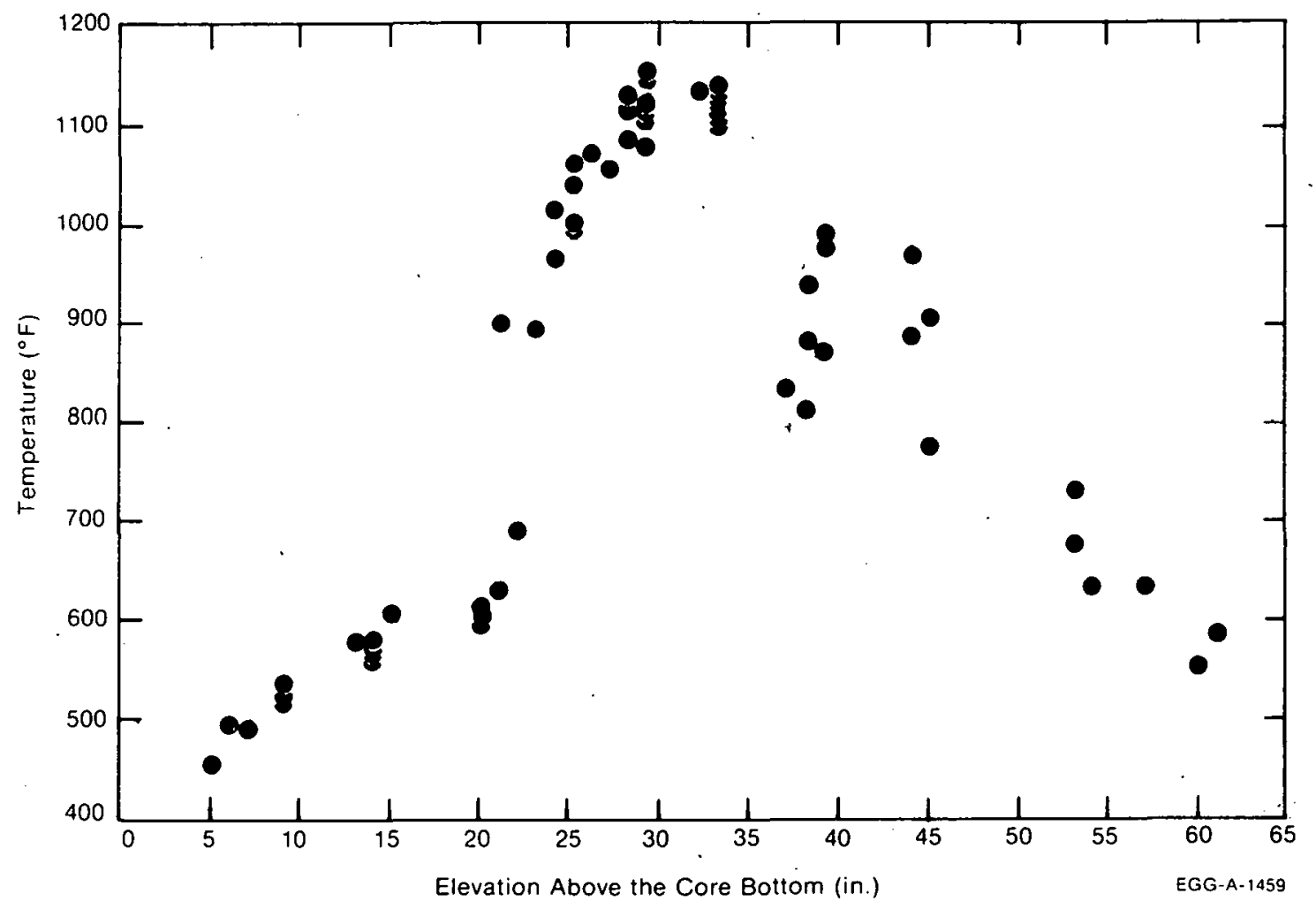

Fig. 25 Rod cladding temperature at the initiation of reflood versus axial core elevation - Test S-29-1.

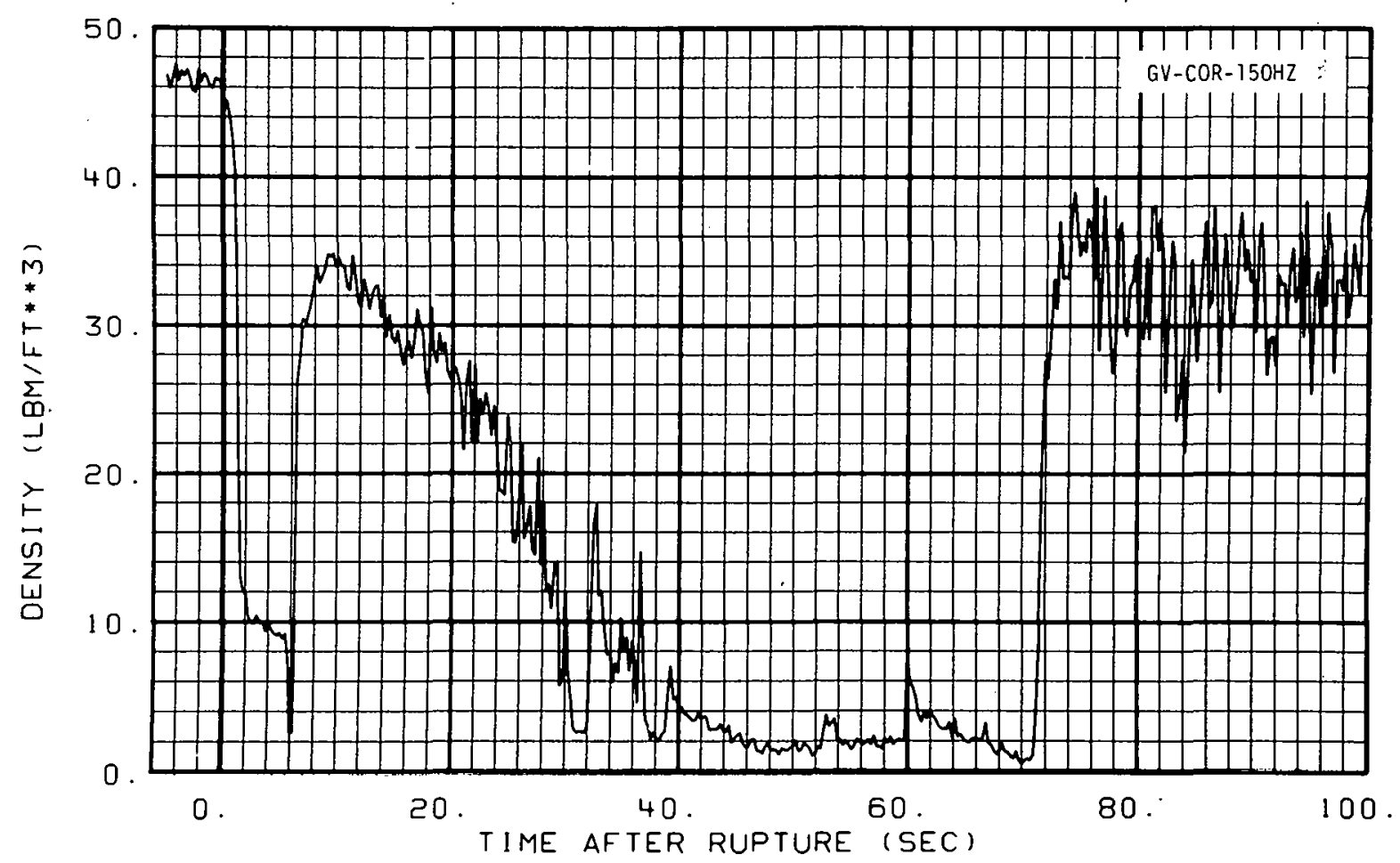

Flg. 26 Fluld density neas die core lintel (0 lo 200 secunds) - Tesi S-29-1. 


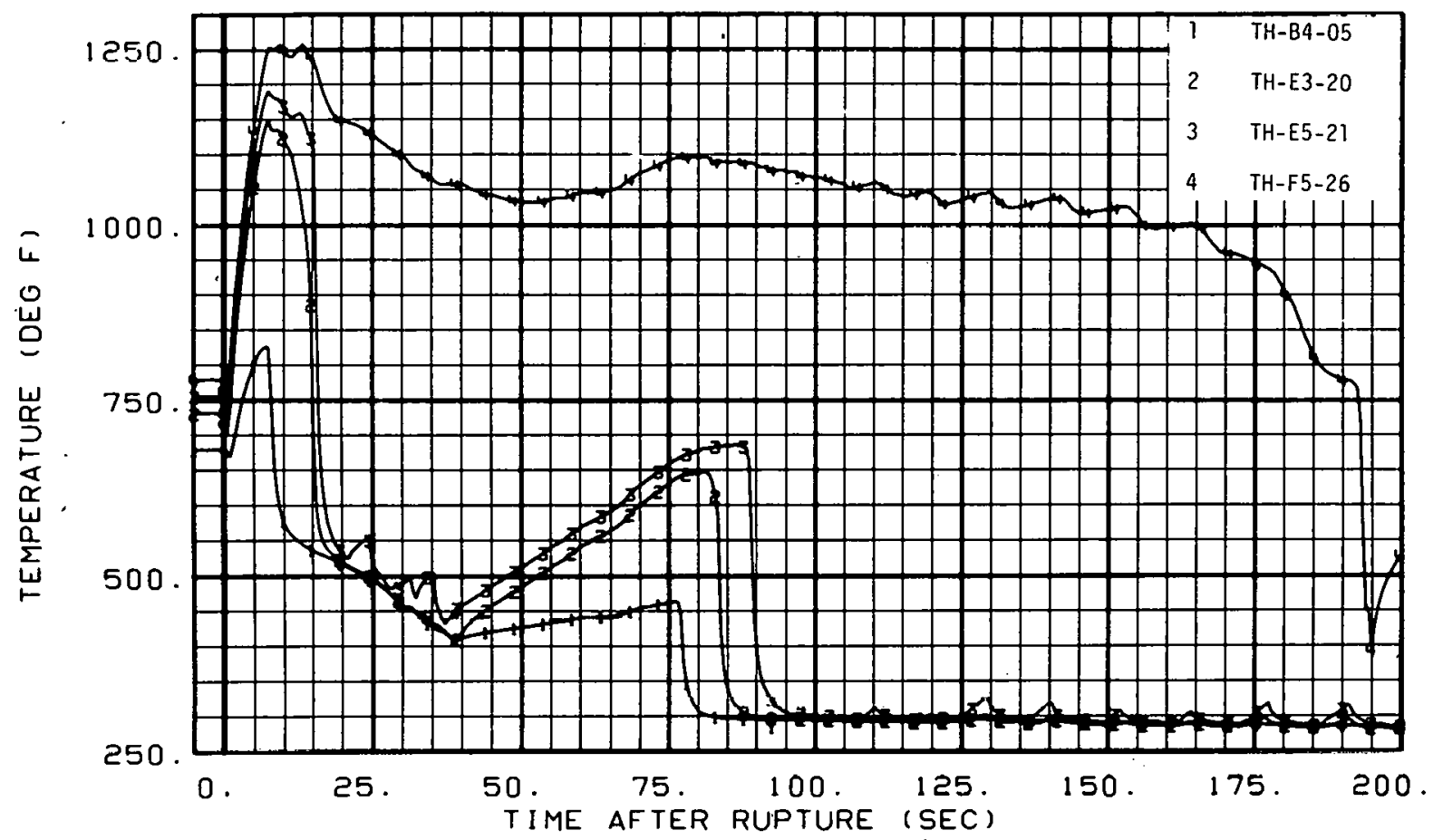

Fig. 27 Rod cladding temperature at the 5-, 20-, 21 -, and 26-in. core elevations on Rods B4, E3, E5, and F5, respectively Test S-29-1.

of about $1.65 \mathrm{in} . / \mathrm{sec}$ and is indicative of a low pressure injection system (LPIS) flow of $3.5 \mathrm{gpm}$. However, the sudden increase in rod surface temperatures between the 21 - and 22-in. core elevations (Figure 25) resulted in a much larger steam generation rate and, consequently, a signiticant reduction in the velocity of the reflood quench front. The reduction in quench front velocity is indicated by the difference in time (with respect to reflood initiation) required for the 21- and 26-in. rod elevations to quench as shown in Figure 27. Furthermore, the data from Test S-29-1 showed that the reflood quench front reached only the 26 -in. core elevation by the end of the test indicating that the rate of LPIS flow was insufficient to remove the stored energy in the rods above the 26 -in. elevation before the end of Test S-29-1 (200 sec).

In summary, the early benefits of the positive core flow and high core heat transfer rates in Test S-29-1 were partially offset by the longer depressurization and the longer ECC bypass periods. The depletion of the intact loop accumulator water before core reflood began placed too heavy of a requirement on the LPIS system. Consequently, reflood of the entire core did not occur before the end of Test S-29-1. 


\section{CONCLUSIONS}

The following conclusions have been reached on the basis of the analysis of results obtained from Test S-29-1.

Neither the core critical heat flux (CHF) time nor the early core post-CHF ( 0 to $5 \mathrm{sec}$ ) heat transfer were appreciably affected by the reduced initial core flow reversal in Test S-29-1. The slight differences in the early core response that were noted between Tests S-29-1 and S-02-7 may have been the result of the different rod powers but, nevertheless, were insignificant in relation to the substantial differences in core flows that existed. However, the Mod-1 core thermal response subsequent to $5 \mathrm{sec}$ was very sensitive to the core inlet flow which was controlled by the size of the vessel side break area. Contrary to the behavior recorded in past cold leg break tests, the smaller vessel side break area in Test S-29-1 resulted in a high density positive core inlet flow within $6 \mathrm{sec}$ after rupture, which led to the advancement of a liquid quench front up to the 21 -in. core elevation during the blowdown transient. This unique core flow behavior during blowdown in Test S-29-1 was accompanied by large increases in heat transfer rates at the rod surfaces when compared to that shown by the data of Test S-02-7. The homogeneous RELAP4 system model miscalculated the core response during this time because a nonhomogeneous flow regime was present.

In Test S-29-1, the steam generation in the core during blowdown due to the advancing quench front resulted in a substantial increase in the duration of the blowdown transient in comparison with results of previous tests. The prolonged blowdown transient resulted in an extended period of high velocity flow of steam up the downcomer and restricted emergency core coolant (ECC) water from the lower plenum until the accumulator was depleted of water and nitrogen injection into the system began. Consequently, the low pressure injection system (LPIS) was the only ECC source in operation during core reflood and the injection from the LPIS system was insufficient to quench the entire core during Test S-29-2. However, the consequences of the reduced effectiveness of the ECC systems in Test S-29-1 due to the prolonged blowdown transient were minimized by the high core heat transfer rates attained during blowdown. 


\section{REFERENCES .}

1. Quarterly Technical Report on Water Reactor Safety Programs Sponsored by the Nuclear Regulatory Commission's Division of Reactor. Safety Research, January - March 1975, ANCR-1 254 (September 1975).

2. T. K. Larson, Core Thermal Response During Semiscale Mod-1 Blowdown Heat Transfer Tests, ANCR-NUREG-1285 (June 1976).

3. H. S. Crapo, M. F. Jensen, K. E. Sackett, Experiment Data Report for Semiscale Mod-1 Test $S$-29-1 (Integral Test with Asymmetrical Break), ANCR-NUREG-1327 (July 1976).

4. K. V. Moore and.W. H. Rettig, RELAP4 A Computer Program for Transient Thermal-Hydraulic Analysis, ANCR-1127, Rev. 1 (March 1975).

5. E. M. Feldman and D. J. Olson, Semiscale Mod-1.Program and System Description for the Blowdown Heat Transfer Tests (Test Series 2), ANCR-1 230 (August 1975).

6. D. J. Hanson et al, ECC Performance in the Semiscale Geometry, ANCR-1161 (June 1974). 


\begin{abstract}
APPENDIX A
DESCRIPTION OF THE RELAP4/MOD-5 UPDATE 1 ANALYTICAL MODEL AS APPLIED FOR TEST S-29-1 CALCULATIONS
\end{abstract}

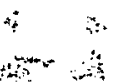




\section{THIS PAGE}

\section{WAS INTENTIONALLY \\ LEFT BLANK}




\section{APPENDIX A \\ DESCRIPTION OF THE RELAP4/MOD-5 UPDATE 1 ANALYTICAL MODEL AS APPLIED FOR TEST S-29-1 CALCULATIONS}

The RELAP4 computer program ${ }^{[\mathrm{A}-1]}$ was developed primarily to describe the blowdown transient behavior of water-cooled nuclear reactors subjected to postulated accidents such as those resulting from loss of coolant. The features of the program that describe the nuclear reactor are optional and as such the program can be applied to experimental water-reactor simulators such as the Semiscale Mod-1 system.

The RELAP4 computer code used in calculating the system response during Test S-29-1 was the RELAP4/MOD5 Update 1 version. The model of the Semiscale Mod-1 system used in the RELAP4 calculation is shown in Figure A-1. The model included 41 control volumes and 47 junctions. Three control volumes were used to represent the vessel lower. plenum and five volumes were used to represent the core region. The vessel inlet annulus and upper plenum were each modeled by a single control volume. Table A-I provides a physical description of the control volumes used in the model and Table A-II describes the fill volumes used to represent the intact and broken loop cold leg low pressure injection system (LPIS) and the intact loop steam generator feedwater supply. A total of 29 heat slabs were used to represent the metal-to-fluid heat transfer which occurred in the simulated core, in tact loop steam generator, and the vessel and piping.

Although the peak power was the same for all rods during Test S-29-1, both the high and low power rods had to be modeled separately due to the differences in the axial power profile. The four high power rods were represented by ten core heat slabs and the 36 low power rods by five core heat slabs as shown in Figure A-2. Power fractions for each heat slab were specified so as to represent the exact power profile for the high and low power rods.

The RELAP4 calculation for Test S-29-1 provided the thermal-hydraulic response of the Semiscale Mod-1 system from initiation of rupture to $38.5 \mathrm{sec}$ following rupture. 


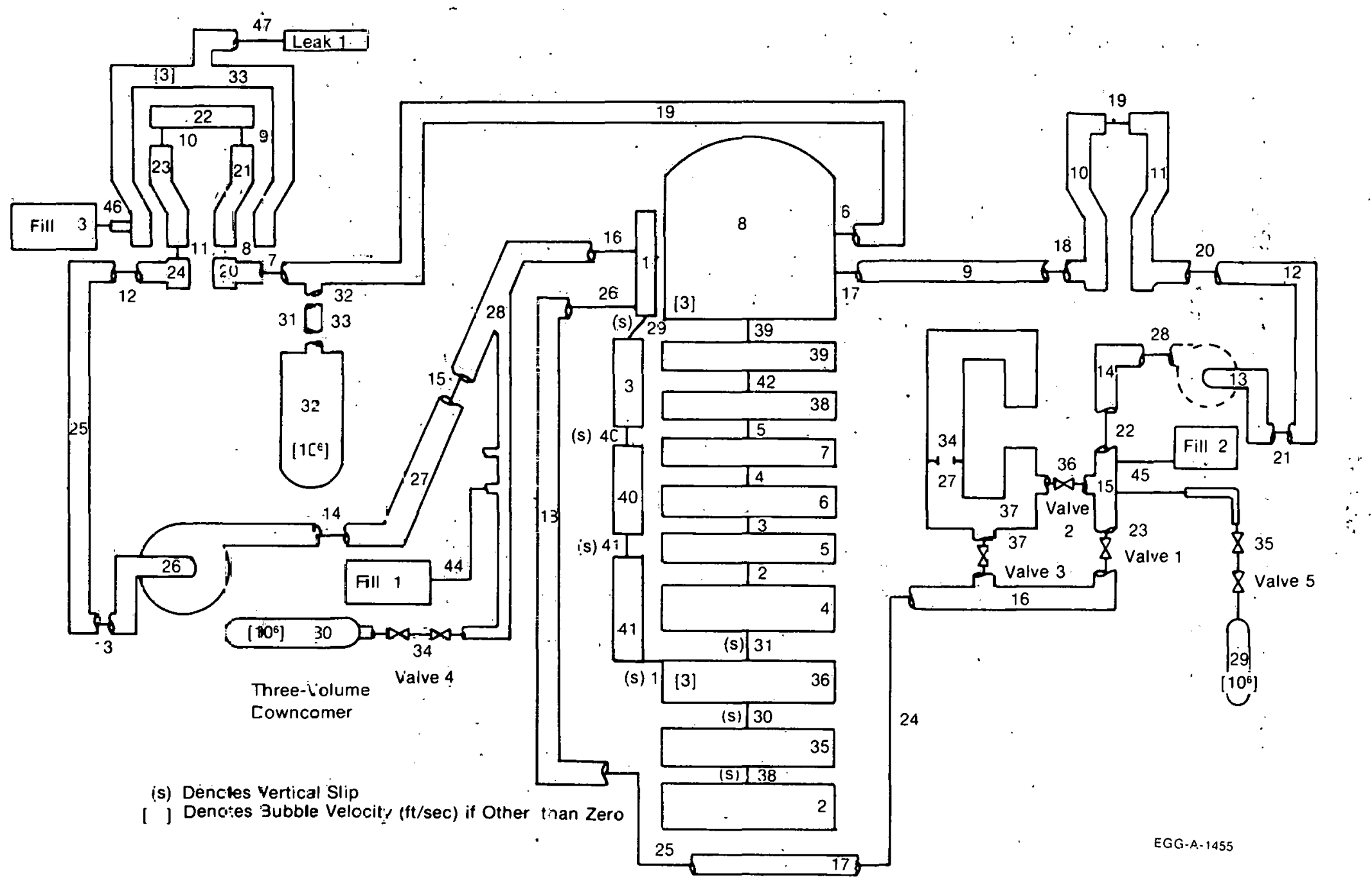

Fig. A-1 REL AP7 model of semiscale system for Test S-29-1. 
TABLE A-I

RELAP4 CONTROL VOLUME DESCRIPTION

\section{Control Volume}

1

2

$3,40,41$

4

$5,6,7\}$

38,39

8

9

10

11

12

13

14

15

16,17

18

19

20

21

22

\section{Description}

Upper annulus

Bottom volume of lower plenum

Downcomer

Mixing box -- immediately below core

Core volumes

Upper plenum

Hot leg -- blowdown loop

Upflow section of simulated steam generator -- blowdown loop

Downflow. section of simulated steam generator -- blowdown loop

Loop closure on blowdown loop

Simulated pump on blowdown loop

Volume in cold leg of blowdown loop adjacent to simulated pump

Volume in cold leg of blowdown loop -accurmulator and LPIS injection volume

Volumes in cold leg of blowdown loop

Volume in cold leg of blowdown loop adjacent to vessel

Hot leg of intact roop

Inlet plenum of active steam generator intact loop

Upflow section of active steam generator intact loop

Uppermost section of tubes in active steam generator -- intact loop 
TABLE A-I' (continued)

\section{Control Volume}

23

24

25

26

27

28

29

30

31

32

33

34

35

36

37

\section{Description}

Downflow section of tubes in the active steam generator -- intact loop

Outlet plenum of active steam generator intact loop

Volume representing the steam generator outlet piping and part of the loop closure

Active coolant pump

Volume lin lhe culd ley or inlacl loup adjacent to the pump

Volume in the cold leg of intact loop adjacent to vessel

Accumulator on blowdown loop

Accumulator on intact loop

Surge line between pressurizer and hot leg -- intact loop

Pressurizer

Secundary side of stean yenerator on intact loop

Pressure suppression vessel

Middle volume of the lower plenum

Top volume of the lower plenum

Control volume representing the inlet header to the pressure suppresston vessel. 
TABLE A-II

\section{RELAP4 FILL SYSTEM DESCRIPTION}

\begin{tabular}{ccl}
\hline Fill Number & Junction & $\frac{\text { Description }}{1}$ \\
& 44 & Pumped ECC, intact loop cold leg \\
2 & 45 & Pumped ECC, broken loop cold leg \\
-3 & 46 & Feed, intact loop steam generator
\end{tabular}

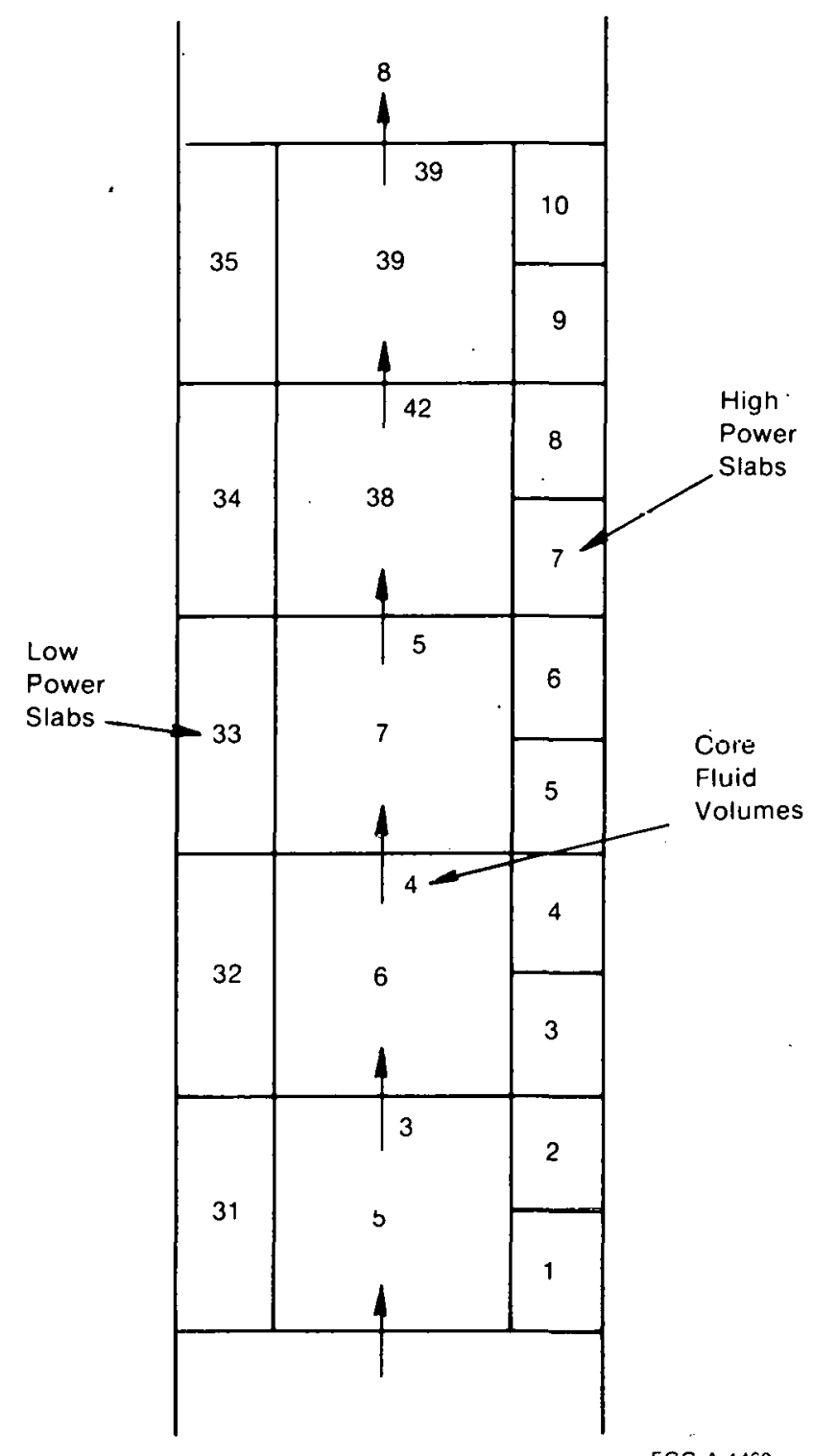

Fig. A-2 Semiscale RELAP4 model of heated core configuration for Test S-29-1. 


\section{REFERENCES}

A-1. K. V. Moore and W. H. Rettig, RELAP4 - A Computer Program for Transient

Thermal-Hydraulic Analysis, ANCR-1 127, Rev. 1 (March 1975). 
DISTRIBUTION RECORD FOR TREE-NUREG-1076

Internal Distribution

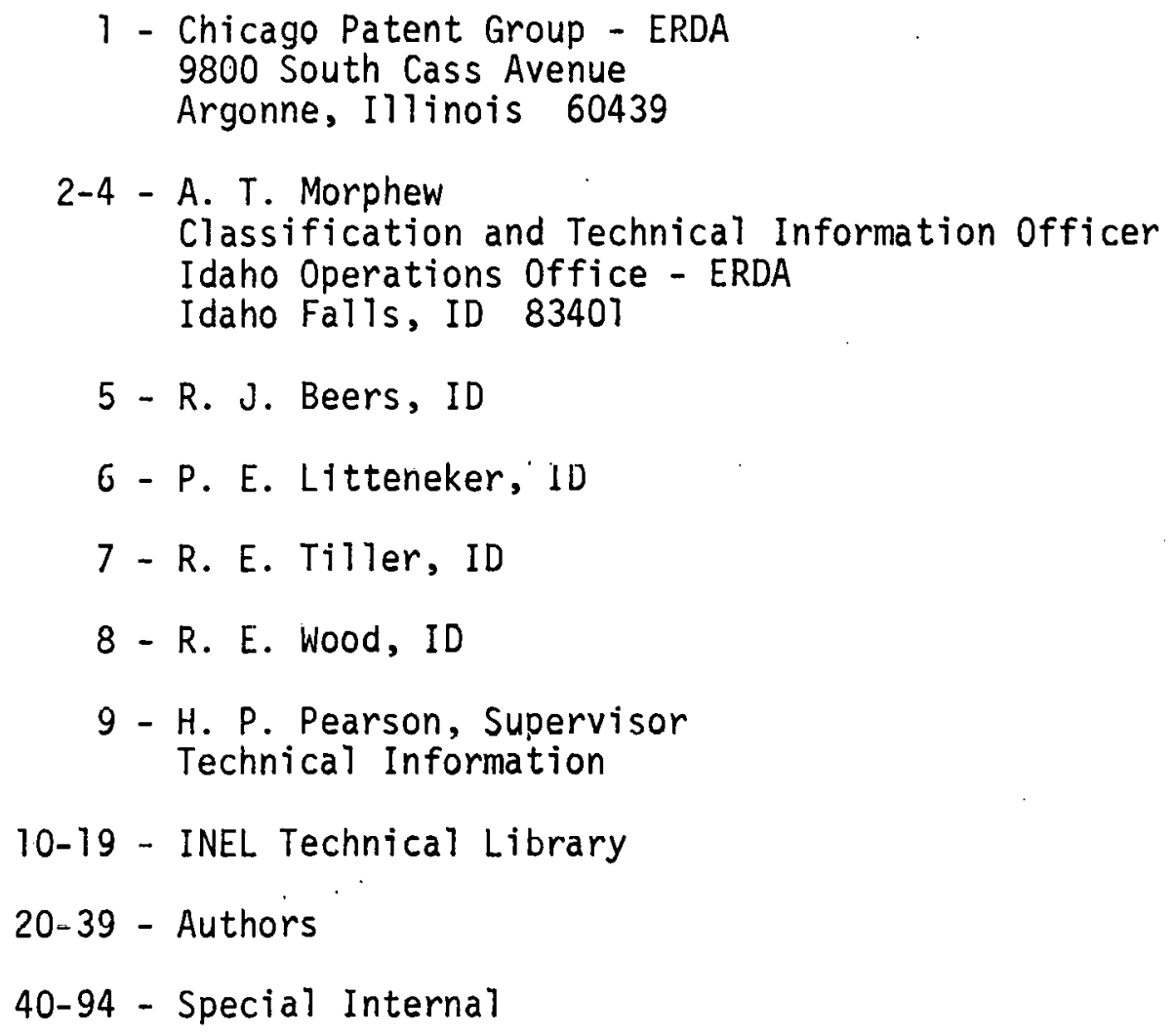

External Distribution

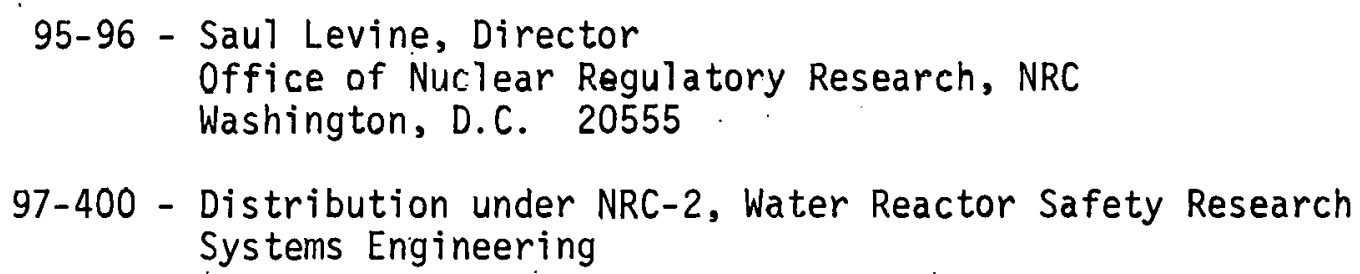

